\title{
Development of Sustainable Indoor Air Quality for Air-Conditioning System Using Smart Control Techniques
}

Tosin T. Oye

School of Engineering and Built Environment, Edinburgh Napier University, UK

\author{
Naren Gupta
}

School of Engineering and Built Environment, Edinburgh Napier University, UK

Keng Goh

School of Engineering and Built Environment, Edinburgh Napier University, UK

Toyosi K. Oye

School of Engineering and Built Environment, Edinburgh Napier University, UK

Received: September 23, 2021 Accepted: November 7, 2021 Published: November 18, 2021

doi:10.5296/emsd.v11i1.19027ＵRL: https://doi.org/10.5296/emsd.v11i1.19027

\begin{abstract}
Air-conditioning as a technical solution to protect inhabitants from excessive heat exposure creates the challenge of expanding indoor health effects. While air-conditioning has mostly been applied as an improvement to living conditions, health and environmental problems associated with its use frequently occurs. Therefore, this paper challenges and extends existing knowledge on sustainability related to the smart air-conditioning systems. The decrease of $\mathrm{CO}_{2}$ level in building requires an intelligent control system because energy utilisation has been legitimately connected with wellbeing and eventually to operational expenses. A building's indoor environmental essential factors of comfort are IAQ, visual and thermal. Through an appropriate structured controller, the performance of indoor control system can be altogether improved. It merits creating innovative control techniques to optimise the indoor environment quality for air-conditioning system. The newly proposed
\end{abstract}


backpropagation neural network was optimised using Matlab to control the $\mathrm{CO}_{2}$ level appropriately while carefully taking into account the performance of system controllers such as the stability, adaptability, speed response and overshoot. The controller of indoor environment was designed, and the proportional-integral-derivative control was utilised as a result of its suitability. The smart controllers were designed to regulate the parameters automatically to ensure the optimised control output. The indoor $\mathrm{CO}_{2}$ possesses an appropriate time constant and settling time of $2.1 \mathrm{~s}$ and $27.3 \mathrm{~s}$, respectively. Therefore, utilising smart control techniques to exterminate various indoor health effects is expected to produce sustainable living conditions.

Keywords: Sustainability, Air-conditioning, Indoor air quality, $\mathrm{CO}_{2}$, Neural networks, Proportional-integral-derivative, Backpropagation

\section{Introduction}

Sustainability was primarily characterised more than 30 years ago and is broadly acknowledged as a significant conceptual framework inside which to situate municipal development and policy. According to Oye et al., (2020a), the basic influence between the related parts of sustainability is subsequently varied amid the understanding of idea which has prompted an assortment of municipal structures being depicted as sustainable. As material utilisation and energy nodes, urban areas are causally connected to quickening worldwide natural deterioration and are not sustainable through themselves. Simultaneously, urban areas and their occupants can undertake a significant work in accomplishing worldwide sustainability (Wilhite, 2009; Campbell, 2013; Oye et al., 2020b). The scholarly investigation of sustainable development currently holds an assortment of points of view and methodologies. It incorporates various practices and policies based on common agrarian utopianism in the direction of capital-intensive large-scale client market growth. The well-being of human is at the focal point of investigation when considering the utilisation of air-conditionings (Kjellstrom et al., 2009; Aftab et al., 2013; Lenzer et al., 2020).

Research studies suggested that air-conditioning has been utilised in numerous places of the world (Mauthner and Weiss, 2014; Oye et al., 2020c). The reason for most systems is to give a satisfactory IAQ and thermal comfort for inhabitants. In like manner, with the development of way of life, inhabitants require increasingly healthy and pleasant indoor environment. In any case, individuals devote $80 \%-90 \%$ of their time indoors, and indoor environment has significant impact on work proficiency and human wellbeing. The components influencing indoor environment for the most part consist of gaseous pollutants, biological pollutants, particle pollutants, ventilation, air movement, air exchange rate, humidity and temperature (Leung, 2015; Oye et al., 2021). Research studies by Yu et al., (2008), Leung (2015), and Oye et al., (2021) also found that there is an expansion in commonness of SBS somewhere in the range of $30 \%-200 \%$ in the structures with air-conditioning when weighed with normal ventilation systems.

One of the results of the overall power disaster in 1970s is the open acknowledgment of the significance of energy saving. The structures worked from that point forward are progressively airtight and utilise a lot of protection materials to limit the loss of energy via 
the structure covering. According to Oye et al., (2021), external air is decreased in air-conditioning to lessen the power utilisation. In the interim, engineered materials and compound items such as decorating and building materials have broadly been utilised indoors. The existence of various manufactured synthetic concoctions and intermingling of low ventilation rates results in raised groupings of VOCs (formaldehyde, toluene and benzene), indoor molecule contaminations, $\mathrm{CO}$ and $\mathrm{CO}_{2}$ emissions. This is regarded to be a noteworthy contributing element to compound excessive cantankerousness (Wang et al., 2004a; Yu et al., 2008; Montero-Montoya et al., 2018; Oye et al., 2021). It is indoor toxins that lead to poor IAQ. Moreover, a number of studies accept that IAQ might be the most significant and moderately ignored environmental issue within recent period (Gao et al., 2012; Tham, 2016; Beama, 2016; WHO, 2018).

As air-conditioning have been generally utilised for healthier thermal comfort in buildings, the issues triggered via poor IAQ happens regularly. IAQ is not an idea that can be effectively characterised, since the awareness of air in an indoor environment is a measure related with different parameters like inhabitant comfort and health. Besides, poor IAQ is positioned as one of the uppermost five environmental dangers to inhabitant wellbeing by the United States Environmental Protection Agency (USEPA) grounded upon comparative risk field studies (Kabrein, 2017; EPA, 2018). Hitherto, subjection to indoor air contaminations is accepted to have expanded because of an assortment of variables, including the development of firmly fixed structures, decrease of ventilation rates for saving energy, and the utilisation of manufactured structure materials and decorations just as synthetically defined individual upkeep items, family unit cleaners and pesticides.

There are various sorts of indoor toxins, for example, indoor particulate matters, $\mathrm{CO}_{2}$, VOCs (Tang et al., 2015, Hamanaka and Mutlu, 2018; Oye et al., 2021). As presented in Table 1, the poor IAQ may trigger a few kinds of health effects such as fatigue, headache chest pain etc. Other serious issue that can trigger poor IAQ is the scent or odour problem that causes numerous effects on human body, for example, mental distraction, efficiency decrease, and so forth as exhibited in Table 2. Subsequently, it is essential to control and monitor IAQ for improving profitability, comfort individuals' health in the built environment. As indicated by previous investigations, ways to deal with and improve IAQ in building can be as per the following (Wolkoff, 2013; Kukadia and Upton, 2019; USEPA, 2020):

- Individual contact estimations, for example nitrogen dioxide as intermediary for introduction to traffic contaminations/combustion

- Black carbon particles: a potential intermediary for ignition particles to assess wellbeing dangers.

- UFP (on-line): size-dispersion and number. Elemental carbon analysis and transition metal.

- High volume inspecting; responsive oxygen species (ROS), for example antioxidant depletion and $\mathrm{OH}$ radicals.

- $\quad$ Sampling of prone species, for example auxiliary ozonides. 
Table 1. Indoor pollutants and their impacts on human health

\begin{tabular}{|c|c|c|c|}
\hline $\begin{array}{l}\text { Indoor } \\
\text { Pollutants }\end{array}$ & Reference & Causes & Health effects \\
\hline $\begin{array}{l}\text { Particulate } \\
\text { matters }\end{array}$ & $\begin{array}{l}\text { Brook et al., } \\
(2010) ; \\
\text { Hamanaka and } \\
\text { Mutlu, (2018); } \\
\text { USEPA (2020). }\end{array}$ & $\begin{array}{l}\text { Outdoor environment, cooking, } \\
\text { combustion activities (burning of } \\
\text { candles, use of fireplaces, heaters, } \\
\text { stoves, fireplaces and chimneys, } \\
\text { cigarette smoking), cleaning } \\
\text { activities. }\end{array}$ & $\begin{array}{l}\text { Premature death in } \\
\text { people with heart or lung } \\
\text { disease, nonfatal heart } \\
\text { attacks, irregular } \\
\text { heartbeat, aggravated } \\
\text { asthma, decreased lung } \\
\text { function, increased } \\
\text { respiratory symptoms. }\end{array}$ \\
\hline VOCs & $\begin{array}{l}\text { Weschler and } \\
\text { Nazaro, (2012: } \\
\text { 2014); Tang et } \\
\text { al., (2015); Oye } \\
\text { et al., (2020b); } \\
\text { USEPA (2020) }\end{array}$ & $\begin{array}{l}\text { Paints, stains, varnishes, solvents, } \\
\text { pesticides, adhesives, wood } \\
\text { preservatives, waxes, polishes, } \\
\text { cleansers, lubricants, sealants, } \\
\text { dyes, air fresheners, fuels, } \\
\text { plastics, copy machines, printers, } \\
\text { tobacco products, perfumes, } \\
\text { dry-cleaned clothing, building } \\
\text { materials and furnishings. }\end{array}$ & $\begin{array}{l}\text { - Eye, nose and throat } \\
\text { irritation } \\
\text { - Headaches, loss of } \\
\text { coordination and nausea } \\
\text { - Damage to liver, kidney } \\
\text { and central nervous } \\
\text { system } \\
\text { - Some organics can } \\
\text { cause cancer }\end{array}$ \\
\hline $\mathrm{CO}_{2}$ & $\begin{array}{l}\text { Wolkoff }(2013) \text {; } \\
\text { Liu et al., } \\
(2014) \text {; USEPA } \\
(2020)\end{array}$ & $\begin{array}{l}\text { Cooking stoves; } \\
\text { smoking; fobacco } \\
\text { and other gasoline powered } \\
\text { equipment; outdoor air. }\end{array}$ & $\begin{array}{l}\text { Fatigue, chest pain, } \\
\text { impaired vision, reduced } \\
\text { brain function, death. }\end{array}$ \\
\hline
\end{tabular}

Table 2. The effects of odour

\begin{tabular}{|l|l|l|}
\hline Irritation Type & References & Symptoms \\
\hline Mental & Atari et al., (2009); Capelli et al., (2019) & Sleeping difficulties \\
\hline Mental & Hoenen et al., (2017); Kontaris et al., (2020) & Tension, Anger \\
\hline Mental & Capelli et al. (2019); Tatiana and Philomena, (2021) & Depressions \\
\hline Mental & Oltra and Sala (2014); Wolkoff (2018) & Confusion \\
\hline Mental & Oltra and Sala (2014); Girard et al., (2016) & Tiredness \\
\hline Gastric & $\begin{array}{l}\text { Capelli et al., (2019); Spence (2020); } \\
\text { Tatiana and Philomena, (2021) }\end{array}$ & Nausea \\
\hline Gastric & Omanga et al., (2014); Steinemann (2017) & Diarrhoea \\
\hline Head & Atari et al., (2009); Kim et al., (2019) & Headache \\
\hline Skin & Atari et al., (2009); Wolkoff and Nielsen, (2017) & Skin rashes \\
\hline Respiratory & Atari et al., (2009); Guo et al., (2016) & Cough \\
\hline Throat & Blanes-Vidal et al., (2014); Wolkoff (2018) & Irritation in throat \\
\hline Eyes & Wolkoff, (2013; 2018) & Irritation in eyes \\
\hline Nose & $\begin{array}{l}\text { Blanes-Vidal et al., (2014); Wolkoff (2018); } \\
\text { Capelli et al., (2019) }\end{array}$ & Irritation in nose \\
\hline
\end{tabular}




\section{Mll Macrothink}

Moreover, research studies reveal that a testing model of IAQ was established in the building setting and grounded upon the European Standard CEN 1752 to decide the outdoor airflow percentage and to confirm the IAQ in housings (Settimo et al., 2020; EC, 2020). Outcomes demonstrate that the climate in rooms influences the wellbeing and the strength of the inhabitants in the meantime. Also, it is exhorted that the architects for structuring and working of air-conditioning should safeguard the wellbeing parameters at the ideal qualities for healthier working and control execution. For the reason to control and operate air-conditioning with the end goal of sustainability, in relation to improve IAQ investigations on sustainable approaches for smart control advancements is required.

Subsequently, studies uncover that there are various kinds of indoor air poisons; however, it is an intricate issue to screen every one of them (EPA, 2018; Manisalidis et al., 2020; Oye et al., 2020). Indoor $\mathrm{CO}_{2}$ concentration analysis and estimation may be valuable for comprehending ventilation and IAQ adequacy (Persily and de-Jonge, 2017; Teleszewski et al., 2019; EC, 2020). Albeit $\mathrm{CO}_{2}$ near $10,000 \mathrm{ppm}$ is adequate to fit individuals without any wellbeing impact, the $\mathrm{CO}_{2}$ level ought to be $650 \mathrm{ppm}$ or held underneath 1,000 ppm over the encompassing level for the purpose of counteracting any gathering of related human odour (ASHRAE Standards 62.1, 2019). Moreover, Table 3 present the damage on human body triggered via high $\mathrm{CO}_{2}$ concentration.

Table 3. The concentration effects of $\mathrm{CO}_{2}$.

\begin{tabular}{|l|l|l|}
\hline $\begin{array}{l}\mathrm{CO}_{2} \\
\text { concentration } \\
{[\mathrm{ppm}]}\end{array}$ & References & Health impacts \\
\hline 500 & $\begin{array}{l}\text { Kajtár and Herczeg, (2012); } \\
\text { MacNaughton et al., (2016); } \\
\text { Vehviläinen et al., (2016); Zhang et } \\
\text { al. (2017) }\end{array}$ & $\begin{array}{l}\text { Increased heart rate, change in heart } \\
\text { rate variability, increased blood } \\
\text { pressure, increased peripheral blood } \\
\text { circulation }\end{array}$ \\
\hline 1000 & $\begin{array}{l}\text { Ezraty et al., (2011); } \\
\text { Carreiro-Martins et al., (2014); } \\
\text { Ferreira and Cardoso (2014); Allen } \\
\text { et al., (2016); Carreiro-Martins et } \\
\text { al., 2016; Zhang et al., (2017) }\end{array}$ & $\begin{array}{l}\text { Level associated with respiratory } \\
\text { diseases, headache, fatigue, difficulty } \\
\text { concentrating in classrooms. } \\
\text { Oxidative stress and damage to DNAin } \\
\text { bacteria (implications for cancer } \\
\text { diseases in humans) }\end{array}$ \\
\hline 10,000 & $\begin{array}{l}\text { Hazardous Substances Data Bank, } \\
\text { (2015); American Conference of } \\
\text { Governmental Industrial } \\
\text { Hygienists, (2017); Tu et al., } \\
\text { (2020) }\end{array}$ & $\begin{array}{l}\text { Cognitive impairment, increased } \\
\text { diastolic blood pressure, increased } \\
\text { respiratory rate, respiratory acidosis, } \\
\text { metabolic stress (decreased blood } \\
\text { calcium or urine phosphorus), } \\
\text { increased brain blood flow, increased } \\
\text { minute ventilation }\end{array}$ \\
\hline 30,000 & $\begin{array}{l}\text { National Institute for Occupational } \\
\text { Safety and Health, (2014); } \\
\text { American Conference } \\
\text { of }\end{array}$ & $\begin{array}{l}\text { Headache, pulse, dizziness, decreased } \\
\text { exercise tolerance in workers when } \\
\text { breathing against inspiratory and }\end{array}$ \\
\hline
\end{tabular}




\begin{tabular}{|c|c|c|c|}
\hline & & $\begin{array}{ll}\text { Governmental } & \text { Industrial } \\
\text { Hygienists, }(2017) & \\
\end{array}$ & expiratory resistance \\
\hline 50,000 & & $\begin{array}{l}\text { National Institute for Occupational } \\
\text { Safety and Health, (2014); } \\
\text { Hazardous Substances Data Bank, } \\
\text { (2015); American Conference of } \\
\text { Governmental } \\
\text { Hygienists, (2017) }\end{array}$ & $\begin{array}{l}\text { Dizziness, headache, confusion, } \\
\text { dyspnea. } \\
\text { May cause death }\end{array}$ \\
\hline $\begin{array}{l}80,000 \\
100,000\end{array}$ & - & $\begin{array}{l}\text { National Institute for Occupational } \\
\text { Safety and Health, (2014); } \\
\text { Hazardous Substances Data Bank, } \\
\text { (2015); American Conference of } \\
\text { Governmental } \\
\text { Hygienists, (2017) }\end{array}$ & $\begin{array}{l}\text { Severe headache, dizziness, confusion, } \\
\text { dyspnea, sweating, dim vision, } \\
\text { hypertension, and loss of } \\
\text { consciousness. } \\
\text { Unexpected death }\end{array}$ \\
\hline
\end{tabular}

ASHRAE stipulated the IAQ standard 62.1, and it reports that: "for comfort, there may be acceptable IAQ if not more than $50 \%$ of the occupants can detect any odour and not more than $20 \%$ feel discomfort, and not more than ten percent suffer from mucosal irritation, and not more than five percent experience annoyance, for less than $2 \%$ of the time" (ASHRAE Standards 62.1, 2019). In essence, to be able to successfully impact most of these issues, sustainable approaches associated with smart control strategies are required to operate air-conditioning, in relation to optimise occupant comfort and significantly saving energy combatting global warming and climate change in built environment.

\section{Utilisation of Neural Network}

According to Liang and Du (2005), Marvuglia et al., (2014), NN controllers are broadly utilised for temperature and thermal comfort regulator of heating systems (hydronic) recognisable proof model of the plant is not obligatory. The $\mathrm{NN}$ is deliberated in this section and the air-conditioning control application instance is provided. Artificial Neural Networks (ANNs) is otherwise called NNs - they process information with their strategy simulated through investigations of the capacity of human cerebrum to gain perceptions and to sum-up in the contemplation (Liang and Du, 2005; Colom et al., 2010; Moyo, 2014).

Dependent on the relating information, NNs can be prepared to learn subjective nonlinear connections. For the set of rules control have been utilised in numerous areas, such as control, discourse handling, design acknowledgment, biomedical designing and so forth. Its benefits additionally depicted consideration of specialists with enthusiasm of control and air-conditioning - ANNs have been practiced with air-conditioning issues. Control techniques structured is dependent upon the ANN set of rules that is utilised for monitoring and simulating present-day heating system suburb and brought about exceptional execution. In the event that these models are prepared with legitimate information; they have great precision, respond fast, information driven and versatile. A number of investigations such as decision-making sustenance for system/plant preservation, training of system/plant machinists, imminent fault, prediction expectation of deprivation, and so forth can be 
analysed, controlled, monitored and simulated through ANNs (De et al., 2007; Dalipi et al., 2016).

For developed thermal control of system/plant, ANNs have been practised progressively. ANNs use transfer functions and connectivity amongst output, input and hidden neurons, undifferentiated from the learning procedure of human cerebrum and has been effectively utilised to systems with uncertain elements or non-direct systems. Specifically, ANNs models are not quite the same as numerical models, for example PID controllers have flexibility via a process of self-tuning. This trademark makes ANNs have the option to precisely settle on choices despite the fact that there is no external skilled involvement when bizarre annoyances, aggravations, as well as fluctuations in structure foundation conditions happen (Moon and Kim, 2010; Sibo et al., 2013). The control system of ANNs has been demonstrated to have focal points in thermal control as far as the exact control of thermal with diminished overcooling, overheating and enhanced energy productivity (Morel et al., 2001; Marvuglia et al., 2014). Research study by Kalogirou (2006) earlier suggested that heating systems stop and start times were resolved by utilising artificial NNs models.

Devabhaktuni et al., (2001), Ding et al., (2004) and Chakraborty (2012) uncovered that NN were originally prepared to model electrical conduct of active and passive circuits/segments. The NNs that are prepared is regularly alluded to as neural models or principally NN models, would then be able to be utilised in design and high-level simulation, giving quick responses to the assignment they have erudite. Modelling techniques and traditional control with significant impediment like observational models, whose precision and range may be restricted or analytical techniques, that may be hard to get for innovative gadgets may be substituted via NNs for better execution or numerical modelling strategies that might be costly through computation. NNs have been utilised in synthesis, measurements, inverse modelling, impedance matching and also, for an extensive collection of air-conditioning applications (Scotton 2012; Ahmad et al., 2016). As a result of this rising technology, a number of researchers and engineers of air-conditioning have started captivating serious awareness in this domain.

Also, basic issues of NNs are presented and famously utilised NN multilayer perception is depicted in the following subsection. Air-conditioning application samples outlining the NN utilisation procedures to modelling of component and optimisation of circuit are exhibited.

\subsection{Typical Neural Network Structure}

There are two sorts of fundamental parts of a NN structure and to be specific: the interconnections between them and processing components. The associations between the neurons are known as connections or neurotransmitters and the processing components are called neurons. Each connection has a comparing parameter weight related with it.

Neurons that get boosts from different neurons with improvements outputs meant for different neurons in the network are identified as hidden neurons. Every neuron gets improvement on different neurons associated with it - they form the data and the output. Improvement neurons on the external network are termed input neurons, even though neurons 


\section{Macrothink}

that the outputs are remotely utilised are termed output neurons. NN structures that is distinctive may be built by utilising various kinds of neurons and by associating them in an unexpected way.

Multilayer perception is a prominently utilised NN structure. The neurons are assembled into layers in the NN multilayer perception. Respectively, the last and first layers are termed output and input layers. Also, hidden layers are termed the remaining layers. Commonly, NN multilayer perception comprises of an output, input and single or further hidden layer. For instance, NN multilayer perception with an output, input and single hidden layer is alluded to as multilayer perception three-layer as appeared in Figure 1.

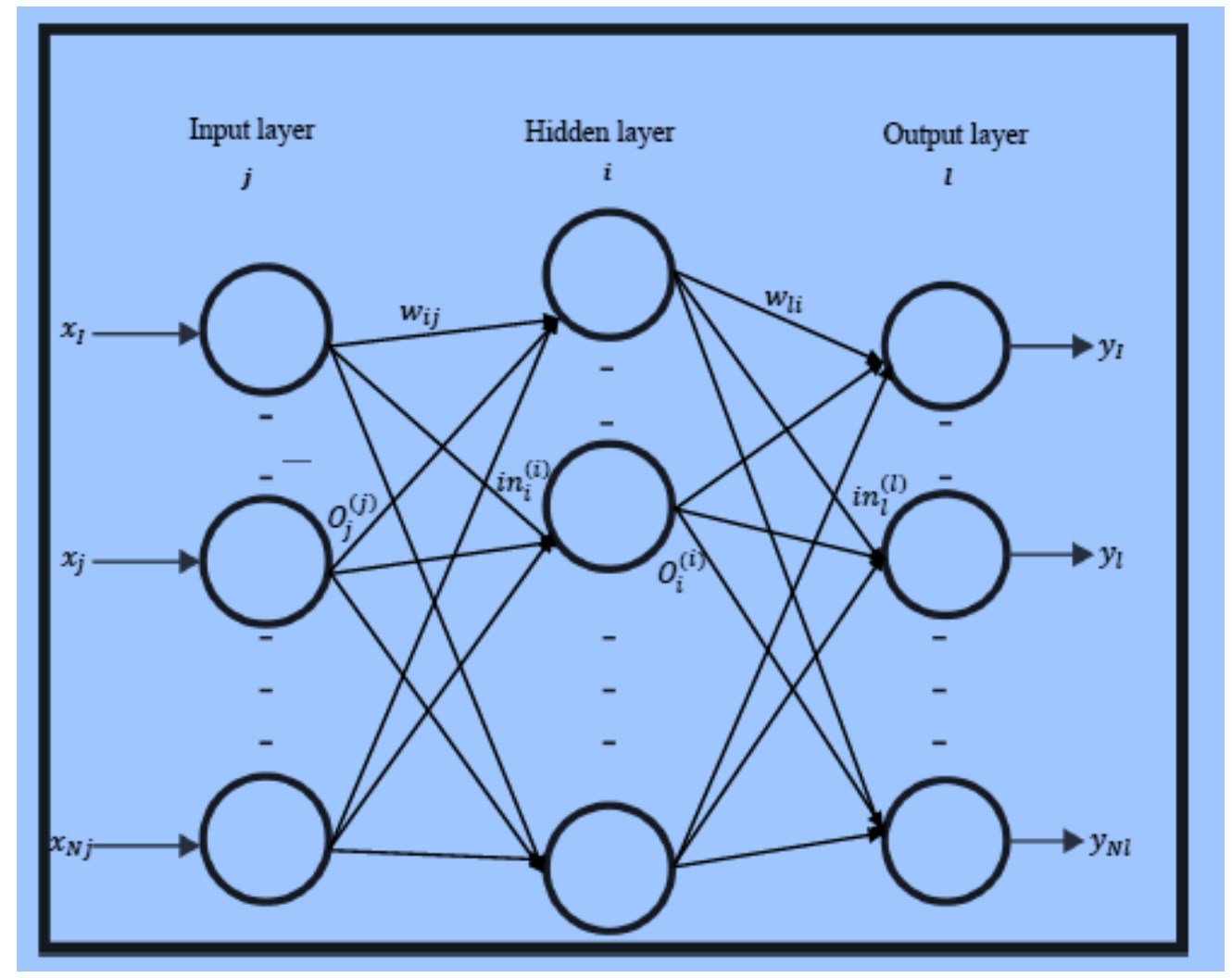

Figure 1. The NN structure (Kamar et al., 2013)

For $i n_{l}^{(l)}$ signifies the outside input and $y_{l}$ is output of $l$ th neuron of output layer. Also, $i n_{i}^{(i)}$ signifies the $i t h$ outside input and $O_{i}^{(i)}$ is the output of ith hidden layer neuron. $x_{j}$ is the input and $O_{j}^{(j)}$ is output of $j t h$ input layer neuron. $w_{l i}$ is the connection weight amongst ith hidden layer neuron and the $\operatorname{lth}\left(i=\left[1,2,3 \ldots \ldots, N_{l}\right]\right)$ output layer neuron. $w_{i j}$ is connection weight amongst $j t h\left(j=\left[1,2,3 \ldots \ldots, N_{j}\right]\right)$ input layer neuron and the ith $\left(i=\left[1,2,3 \ldots \ldots, N_{i}\right]\right)$ hidden layer neuron. Neurons number in the input layer is $N_{j}$, output layer is $N_{l}$, and hidden layer is $N_{i}$. 


\section{Macrothink}

Every neuron in the network multilayer perception forms the inputs established from different neurons. The procedure is completed via a capacity in the neuron termed the activation function and the prepared data turns into the neuron output. For instance, each neuron gets upgrades in the hidden layer from input layer neurons. For ith hidden layer neuron forms the data in two stages.

Every of the input is mainly reproduced through the equivalent parameter weight and the outputs are supplementary to yield a sum weight $i n_{i}^{(i)}$ specified as:

$$
i n_{i}^{(i)}=\sum_{j-1}^{4} w_{i j} O_{j}^{(j)}
$$

The sum weight subsequently in equation 1 is utilised to dynamic the function of neuron's activation to yield the ultimate neuron output $O_{i}^{(i)}$ given as:

$$
O_{i}^{(i)}=f\left(i n_{i}^{(i)}\right)
$$

This yield can thus, convert upgrade to output layer neurons. The greatest generally utilised activation function hidden neuron is termed sigmoid function since it is a function that is smooth switch and persistently differentiable, monotonic, continuous and bounded. Additional hyperbolic-tangent circular and arc-tangent function, and so on. It may be utilised as the function of actuation; however, activation function hidden neuron that is termed sigmoid function is specified as:

$$
f(x)=\frac{1}{\left(1+e^{-x}\right)}
$$

\subsection{Suitable Network Size}

Hidden neurons of appropriate number are expected to guarantee the $\mathrm{NN}$ to be a precise model to become familiar with the focused-on issue. Hidden neurons number relies on the level of nonlinearity of $f$ and the output $y$ and input $x$ dimensionality. Additional neurons are required for the exceptionally nonlinear systems and components even though less are required for items that are smoother. Besides, the all-inclusive estimate hypothesis does not indicate concerning what ought to be the multilayer perception network size. The exact hidden layers neurons and number of them mandatory for a specified task-based modelling stays an open inquiry since trial-and-error method can be applied to decide hidden neuron numbers. Adaptable procedures which include/erase neurons all through the training period may be utilised to decide suitable neurons number (Devabhaktuni et al., 2001; Alvarez and Salzmann, 2016). Progressive data level in the first modelling issue may stay replicated through multilayer perception layer numbers. As a consequence, applications of air-conditioning generally necessitate a couple of multilayer perceptions hidden layers (such as multilayer perceptions that involve three-or four-layer) (Bonala, 2009). 


\subsection{Techniques of Neuro-Fuzzy}

According to Bosque et al. (2014), systems of neuro-fuzzy allude to the systems where the methods of NN were utilised in fuzzy innovation. The hybrid system like ANFIS (Adaptive Neuro-Fuzzy Inference System) have earlier been utilised for control and forecast of artificial lighting in structures, ensuing diversities of normal lighting (Kurian et al., 2005; Popoola, 2016). Prescient control technique that is well-planned, joined with structure modelling, operators' conduct, and the forecast of climate parameters may keep-up the indoor conditions in an ultimate comfort level and also accomplish energy savings. Neural controller that is prepared with the expectational abilities of NNs may be adjusted to solar buildings and the hydronic systems of heating control (Argiriou et al., 2004; Ghadi et al., 2014).

Research study by Argiriou et al., (2004) created and tried a controller for adaptive NN for single zone control of hydronic systems heating. The controller outputs and inputs are parameters connected with set point temperature and device heating. Besides, this control neglects to exhibit phenomenal execution of control as no anticipating of any indoor conditions or climate parameters is engaged with the control procedure. In like manner, Hassan and Kothapalli (2010) suggested a controller of fuzzy-PI that modifies NN. However, it ignores to provide a remarkable development. Notwithstanding, study by Rami and Al-Jarrah and (2013) present control algorithms of an air-conditioning that joins predictive control, fuzzy systems and NNs. This scheme incorporated the climate parameters forecast and inhabitants' number that expectations are then examined to evaluate the performance of building to accomplish energy saving and ensure comfort that is acceptable. For this shows that control execution improvement can be accomplished through joining the benefits of advanced and conventional control strategies.

\subsection{Optimisation Technique}

For minimisation of an error (or objective) function as indicated by Ari et al., (2005), the optimisation procedure of the gradient regulates direction search. This method can be utilised for energy consumption minimisation in circulated environmental systems control whereas sustain a top inhabitant level of comfort. The most broadly utilised subordinate free procedures are namely, downhill simplex method, random search, simulated annealing and GAs. GAs are search-adaptive and algorithm optimisations that work through impersonating normal genetic standards (Jaen-Cuellar et al., 2013). For the algorithms are not quite the same as techniques of optimisation and customary search utilised in project engineering matters. Major thoughts are obtained on genetics and are artificially utilised to build algorithms search that are vigorous and necessitate negligible issue correlated data. Besides, study by Alcala et al., (2003) earlier analysed the utilisation of natural gas to progress FLC that is smartly tuned for air-conditioning, with the end goal of indoor comfort and energy performance enhancement. Moreover, Mossolly et al., (2009) proposed a system with GAs for air-conditioning on-line control to brand the controller of the air-conditioning as a control system that is self-learning. 


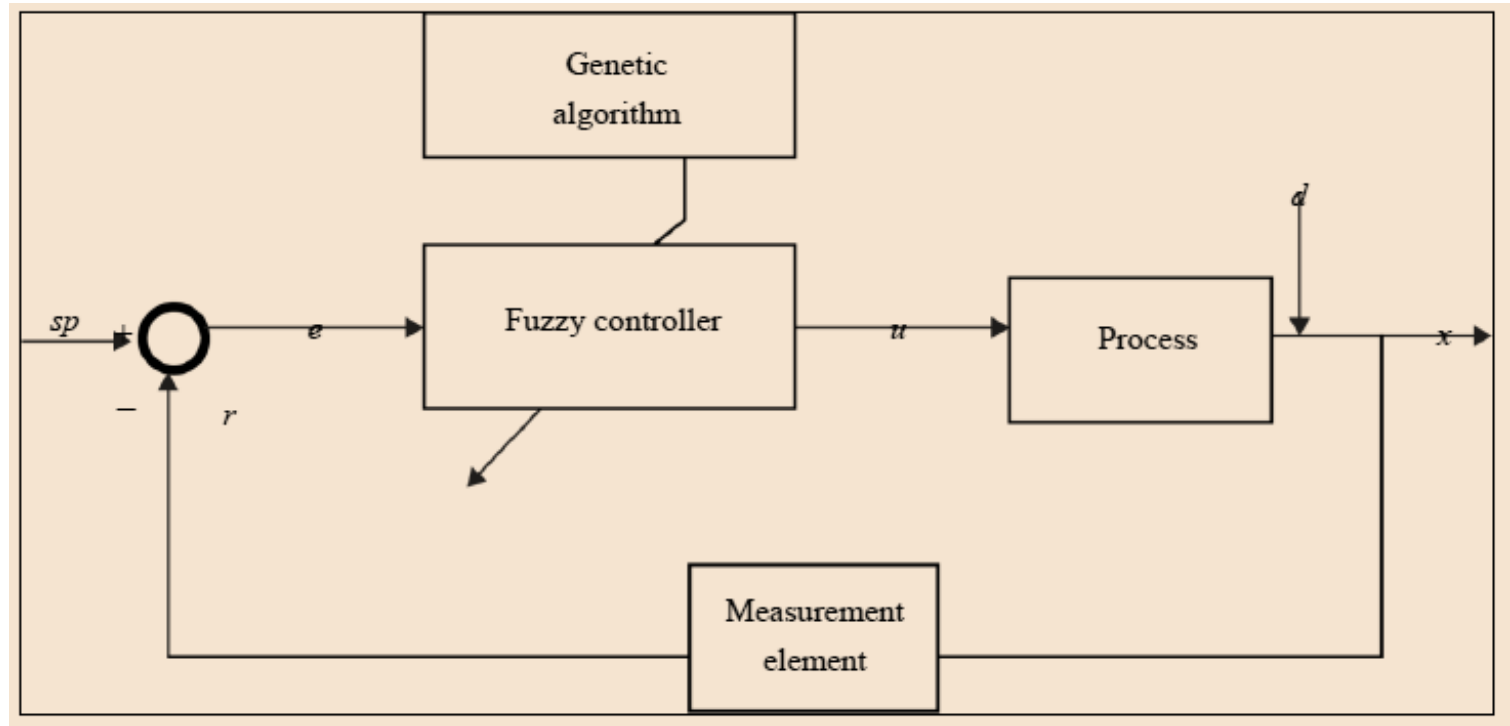

Figure 2. Utilising GA and fuzzy controller (Altinten et al., 2006)

$\mathrm{d}=$ disturbance; $\mathrm{e}=$ =rror; $\mathrm{r}=$ measurement value; $\mathrm{u}=$ controller output; $\mathrm{x}=$ =process output; $\mathrm{sp}=\mathrm{set}$ point.

Research study by Altinten et al. (2006) anticipated a structured fuzzy control utilising GA as offered in Figure 2 for the control of temperature. The function fitness for GA is selected as absolute integral value error and used to characterise the function of fuzzy membership as specified in Figure 3 and Figure 4, respectively. Through utilising parameters of fuzzy indicated at steady temperatures, the fuzzy controller efficiency with GA is inspected through experiment and simulation. It is seen in Figure 5 that GA can efficiently tune the fuzzy controller for various circumstances and for temperature control.

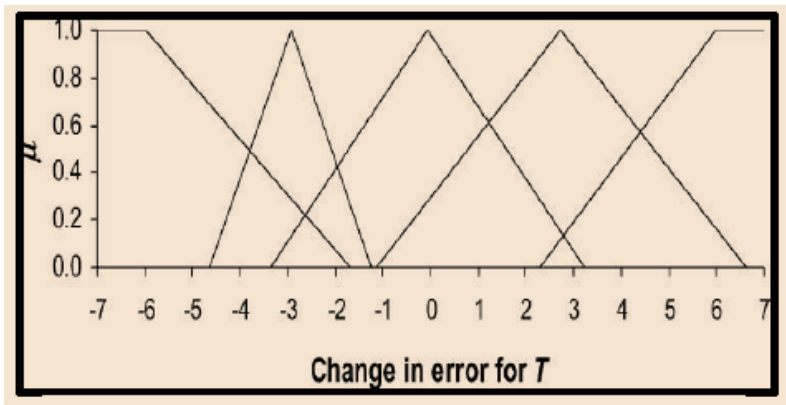

Figure 3. Change in error fuzzy membership functions for temperature (Altinten et al., 2006) 


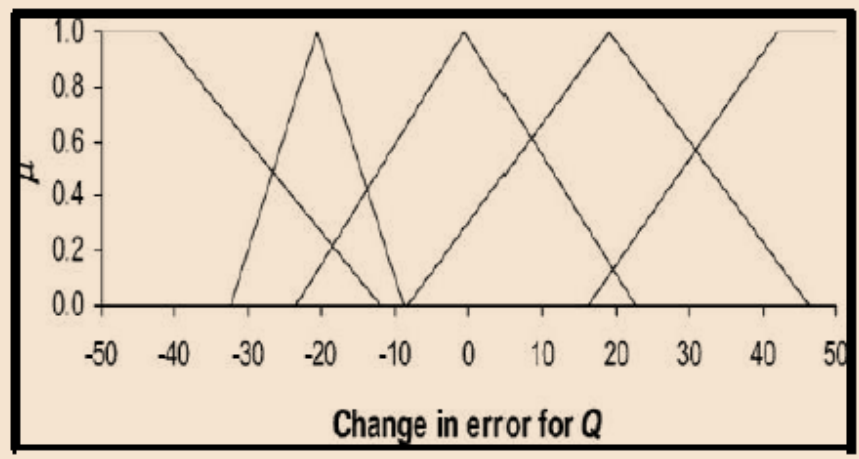

Figure 4. Change in error fuzzy membership functions for heat (Altinten et al., 2006)

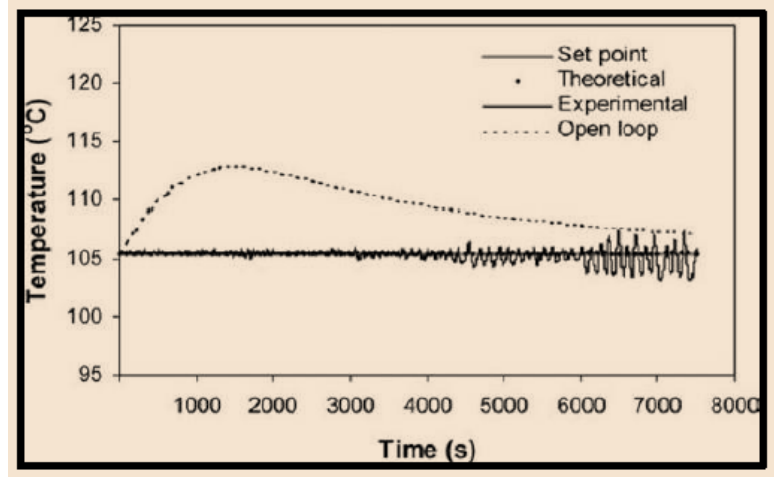

Figure 5. Fuzzy genetic control of temperature (Altinten et al. 2006)

As indicated by these investigations, the propelled algorithm control can accomplish substantial energy saving contrasted with systems of the traditional control; albeit energy saving and IAQ level relies upon the technology control and likewise, building qualities, climate conditions and preferences of the user. For energy saving and built environment control, the illustration and discussion exhibit that smart control systems have been utilised (Oye et al., 2020d). Nevertheless, existing control approaches for air-conditioning can be synopsised in Table 4 below:

Table 4. The existing control approaches.

\begin{tabular}{|l|l|}
\hline Existing Control Approaches \\
\hline Customised design & $\begin{array}{l}\text { Conventional control methods like PID control should be designed } \\
\text { according to the model of the building, and model mismatch will } \\
\text { produce poor control performance. Even for an adaptive controller, } \\
\text { such knowledge is still required at extent (De-Maity and Mudi, 2015; } \\
\text { Doroshenko, 2017). }\end{array}$ \\
\hline Application difficulty & $\begin{array}{l}\text { The fuzzy controllers' weak points are due to the difficulty of } \\
\text { identifying precise membership functions and lack of adequate } \\
\text { methodical technique for expert knowledge transformation into the }\end{array}$ \\
\hline
\end{tabular}




\begin{tabular}{|l|l|}
\hline & $\begin{array}{l}\text { rule base. Besides, parameters tuning takes time. NN can automatic } \\
\text { the process of tuning parameters, substantially decrease the time of } \\
\text { development and outcomes in an improved performance. } \\
\text { Nevertheless, in NNs, both knowledge representation and } \\
\text { knowledge extraction are challenging (Gomes, 2012; Marvuglia et } \\
\text { al., 2014; Moyo, 2014). }\end{array}$ \\
\hline $\begin{array}{l}\text { Applying advantage } \\
\text { controls }\end{array}$ & $\begin{array}{l}\text { Operators having an expert knowledge with certain skills are } \\
\text { required which restricts the usefulness of such controllers (Behrooz } \\
\text { et al., 2018). }\end{array}$ \\
\hline $\begin{array}{l}\text { Lag-behind } \\
\text { air-conditioning } \\
\text { development } \\
\text { technologies }\end{array}$ & $\begin{array}{l}\text { Existing control algorithms do not have appropriate control } \\
\text { performance and do not offer precise control for these } \\
\text { air-conditioning (Behrooz et al., 2018). }\end{array}$ \\
\hline
\end{tabular}

In the Table 5 below, technology control improvement is required in certain domains to address the inadequacies of the air-conditioning existing control technologies. Moreover, this will even unfold better understanding of control systems associated with the renewable-based smart/intelligent air-conditioning.

Table 5. Requirement of technology control improvement

\begin{tabular}{|l|l|}
\hline \multicolumn{2}{|l|}{ Improvement of Control Technology } \\
\hline (i) & $\begin{array}{l}\text { For better performance and more efficiency, new control approach for advanced } \\
\text { air-conditioning can be considered (Esfandyari et al., 2013). }\end{array}$ \\
\hline (ii) & $\begin{array}{l}\text { For model matching and parameters tuning, model-independent control approaches for } \\
\text { general use which can lessen the time of development can be considered. This is } \\
\text { important as air-conditioning are broadly applied in buildings (Ghadi et al., 2014; } \\
\text { 2018). }\end{array}$ \\
\hline (iii) & $\begin{array}{l}\text { Addition of other signals which have connection with the indoor environment quality in } \\
\text { the process of control to enhance the control of energy and indoor environment quality } \\
\text { performance (Ghadi et al., 2014; 2018). }\end{array}$ \\
\hline
\end{tabular}

\section{Methodology}

\subsection{Scenario Modelling of Indoor Air Quality $\left(\mathrm{CO}_{2}\right)$}

There are diverse kinds of indoor contamination within the indoor environment, and it is unimaginable to expect to control and monitor the entire indoor pollutants. Hence, one contaminant that is predominant, which necessitates the utmost measure of natural air to weaken such pollutant to an adequate level is chosen in this examination as the control signal for the control methodology. The indicator analysed is the indoor $\mathrm{CO}_{2}$. By way of controlling indoor $\mathrm{CO}_{2}$ to the ideal levels, the greater part of the other indoor air contaminations may be kept up at adequate levels. The concentration of the indoor $\mathrm{CO}_{2}$ can be specified as (Oye et 
al., 2020b):

$$
V_{i} \frac{d C_{i c o_{2}}}{d \tau}=E_{\mathrm{Co}_{2}}-\lambda \cdot V_{i} \cdot C_{i c o_{2}}-f \cdot\left(C_{i c o_{2}}-C_{\mathrm{OCo}_{2}}\right)
$$

Where, $C_{i c o_{2}}(p p m)$ is the indoor $\mathrm{CO}_{2}$ concentration, $E_{\mathrm{Co}_{2}}(p p m / s)$ is the average $\mathrm{CO}_{2}$ emanation rate of each person in the indoor environment, $\tau(s)$ is the time, $\lambda\left(s^{-1}\right)$ is the $\mathrm{CO}_{2}$ decay constant, $V_{i}\left(\mathrm{~m}^{3}\right)$ is the volume of the room, $C_{i c o_{2}}(p p m)$ is the indoor $\mathrm{CO}_{2}$ concentration, $f\left(\mathrm{~m}^{3} / \mathrm{s}\right)$ is the volume flow rate of the supplied air, $C_{\text {oco }_{2}}(p p m)$ is the outdoor $\mathrm{CO}_{2}$ concentration.

Taking Laplace transform of the equation 4, it can be expressed as:

$$
V_{i} \text { s. } C_{i \mathrm{CO}_{2}}=E_{\mathrm{Co}_{2}}-\lambda . V_{i} \cdot C_{i c \mathrm{O}_{2}}-f . C_{i \mathrm{Co}_{2}}+f . C_{\mathrm{OCo}_{2}}
$$

Rearranging the above equation, it can be expressed as:

$$
V_{i} \text { s. } C_{i c o_{2}}+\lambda \cdot V_{i} \cdot C_{i c o_{2}}+f \cdot C_{i c o_{2}}=E_{\mathrm{Co}_{2}}+f \cdot C_{\mathrm{OCo}_{2}}
$$

Taking $C_{\mathrm{ico}_{2}}$ common from left side and assuming $f . C_{\mathrm{OCo}_{2}}=0$, the transfer function of the indoor $\mathrm{CO}_{2}$ model can be expressed as:

$$
\frac{C_{i c o_{2}}}{E_{c o_{2}}}=\frac{1 / \lambda V_{i}+f}{V_{i} / \lambda V_{i}+f \cdot s+1}
$$

Putting $T_{i c o_{2}}=\frac{V_{i}}{\lambda \cdot V_{i}+f} \quad$ which is the system time constant, it can be expressed as:

$$
\frac{C_{i c O_{2}}}{E_{\mathrm{CO}_{2}}}=\frac{T_{i c \mathrm{O}_{2}} / V_{i}}{T_{i c o_{2}} \cdot S+1}
$$

By converting s-domain transfer function to z-domain and rearranging the transfer function, it can be expressed by dividing the denominator and nominator as follows:

$$
\frac{C_{i c o_{2}}}{E_{C o_{2}}}=\frac{1 / V_{i}}{s+1 / T_{i c o_{2}}}
$$

Since z-transform is as follows:

$$
1 / s+a=\frac{z}{z-\exp (-a t)}
$$

Hence, the transfer function becomes:

$$
\frac{C_{i c o_{2}}}{E_{C o_{2}}}(z)=\frac{\left(1 / V_{i}\right) z}{z-\exp \left(-1 / T_{i c o_{2}}\right)}
$$

\subsection{Backpropagation Neural Network PID Controller}

The concentration of indoor $\mathrm{CO}_{2}$ analysis and measurement may be beneficial for 
comprehending ventilation and IAQ efficiency. The IAQ control trouble is the dimension errors and delay of time. Nonetheless, for the goal to attain the system best performance regarding small overshoot, interference resistance, systemic stability and response speed, a backpropagation NN that is based upon algorithm weight update with PID controller is anticipated.

In this section, the algorithm and structure of the backpropagation NN with PID controller is presented. The backpropagation NN with PID performance is substantiated through computer simulation by way of applying Matlab program as deliberated upon in the section 4 .

\subsubsection{Backpropagation Neural Network PID Controller Structure}

In this paper, Figure 6 offers the intelligent PID controller structure which is grounded upon the learning algorithm of backpropagation NN. For it comprises two divisions:

- backpropagation NN and,

- typical PID controller

The PID controller is scrutinised to control the entity of the environment IAQ. The performance control is contingent upon the parameters, $k_{p}, k_{i}$ and $k_{d}$ setting of the PID control that can be auto tuned through backpropagation NN. The backpropagation NN utilises algorithm of on-line training, grounded upon approach of descent gradient to update weights of the network and guarantees that the $\mathrm{NN}$ which is designed can calculate the required parameters of PID control for the PID controller. Through connecting the intelligent backpropagation NN with the typical PID in this method, the chosen system output can be pursued with a definite constancy.

\subsubsection{Algorithm of PID Control}

The gradational digital control algorithm of PID can be conveyed as:

$$
\begin{gathered}
u(k)=u(k-1)+k_{p}\left\{e_{y}(k)-e_{y}(k-1)\right\}+k_{i} e_{y}(k)+k_{d}\left\{e_{y}(k)-2 e_{y}(k-\right. \\
\left.1)+e_{y}(k-2)\right\}
\end{gathered}
$$

Thus, $k_{d}$ is term of the derivative, $k_{i}$ is term of the integral, $k_{p}$ is term of the proportion, $u$ is the output of the PID controller and $e_{y}$ is error of the system. This can be conveyed in equation 13 , while $r$ is the actual system output and $y$ is the targeted system output.

$$
e_{y}(k)=r(k)-y(k)
$$

\subsubsection{Algorithm of Backpropagation Neural Network}

Therefore, whether the NN possess enough neurons, it can estimate single hidden layer of whichever incessant function (Ken-Ichi, 1989 and Hui et al., 2006). Hence, single hidden layer of NN is depicted. For the anticipated strategy having four-input-three-output revealed in Figure 7 is the backpropagation NN possessing triple layers such as the output layer, input layer and single hidden layer. Nevertheless, the adjustment weights rule of backpropagation 


\section{Macrothink \\ Environmental Management and Sustainable Development \\ ISSN 2164-7682 \\ 2022, Vol. 11, No. 1}

and the progressive feed algorithm is deliberated thoroughly in this section.

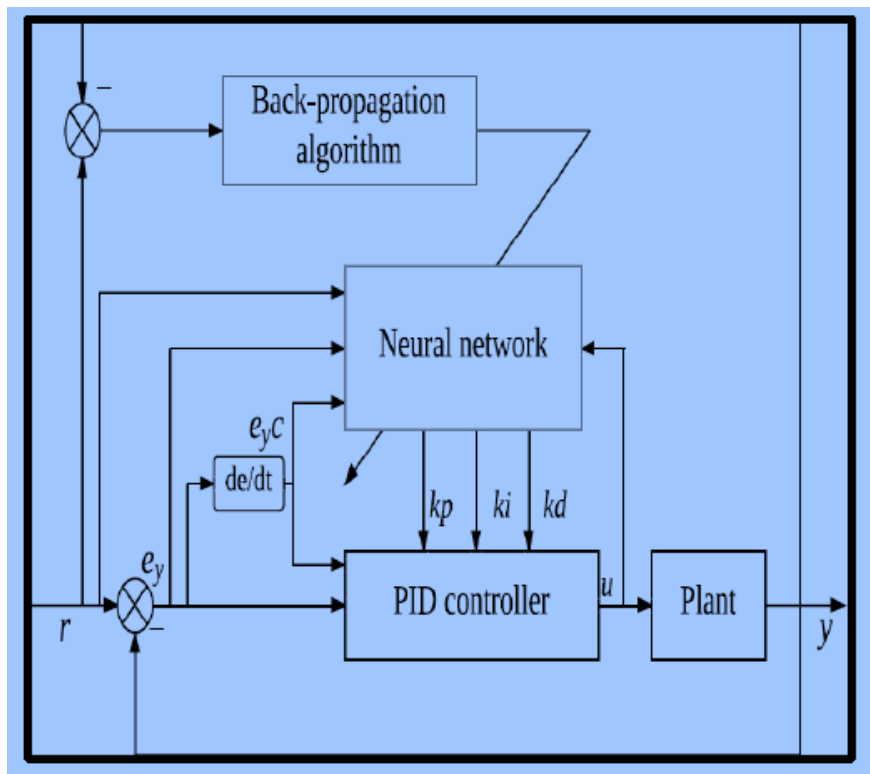

Figure 6. Structure of backpropagation NN based on PID control

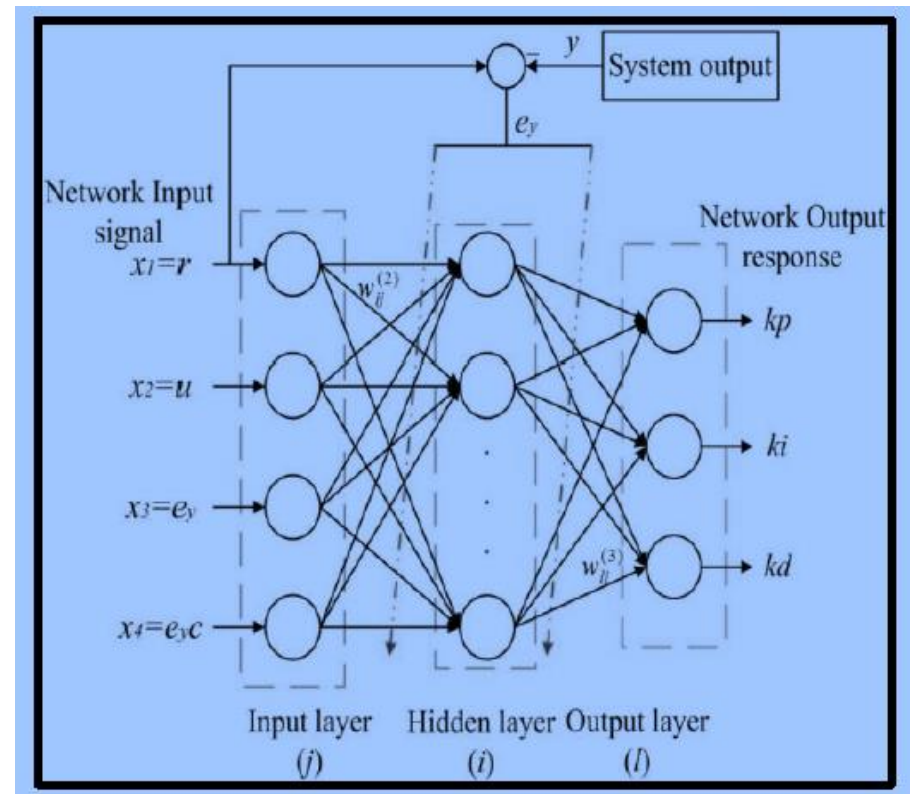

Figure 7. Algorithm structure of backpropagation NN

\section{Scenario Control-Based Feed Forward}

As shown in both Figure 6 and Figure 7, the NN that is designed possesses four inputs as conveyed below in equation 14 : 


$$
\left\{\begin{array}{l}
x_{1} \\
x_{2} \\
x_{3} \\
x_{4}
\end{array}\right\}=\left\{\begin{array}{c}
r \\
u \\
e_{y} \\
e_{y} c
\end{array}\right\}
$$

Thus, $u, e_{y}$ and $r$ are explained in equations 12 and 13 respectively, whereas $e_{y} c$ is the system error changing rate $e_{y}$ which is conveyed as:

$$
e_{y} c(k)=e_{y}(k)-e_{y}(k-1)
$$

In the input layer, individually neuron output is conveyed as follows:

$$
O_{j}^{(1)}=x(j) \quad\{j=1,2,3,4\}
$$

For the superscript one which is illustrated in equation 16 as $\left({ }^{1}\right)$ is specifically positioned for input layer in the algorithm that is designed. Also, the hidden layer NN of individually neuron input can be calculated grounded upon the input layer output. This is conveyed in equation 17 below as:

$$
i n_{i}^{(2)}(k)=\sum_{j=1}^{4} w_{i j}^{(2)} O_{j}^{(1)} \quad\{i=1,2, \ldots, N\}
$$

For the superscript two which is illustrated in equation 17 as $\left(^{2}\right)$ is subsequently positioned for hidden layer whereas, the weight linking the neurons hidden layer to the neurons input layer is $w_{i j}^{(2)}$ and neurons number within hidden layer is $N$. Therefore, individually neuron output within hidden layer $\mathrm{NN}$ can be conveyed in equation 17 as:

$$
O_{i}^{(2)}(k)=f\left(i n_{i}^{(2)}(k)\right)
$$

In the hidden layer, the function of activation is $f(x)$ and it subsequently offers the association amongst individually output and input neuron. In any case, the function of symmetrical sigmoid is utilised consequently as the function of activation and conveyed in equation 19 as:

$$
f(x)=\tanh (x)=\frac{e^{x}-e^{-x}}{e^{x}+e^{-x}}
$$

When individually neuron output in hidden layer is designed, individually neuron input within the output layer can be specified in the equation 20 as follows:

$$
i n_{l}^{(3)}(k)=\sum_{i=1}^{N} w_{l i}^{(3)} O_{j}^{(2)}(k) \quad\{l=1,2,3\}
$$

Thus, the superscript three which is illustrated in equation 21 as $\left({ }^{3}\right)$ is positioned for the output layer whereas, the weight linking the neurons output layer to the neurons' hidden layer 
is $w_{l i}^{(3)}$. The output layer neurons number is three and the neurons outputs are the parameters of PID. Individually neuron output within output layer is specified via the subsequent equations below:

$$
\begin{gathered}
O_{l}^{(3)}(k)=g\left(i n_{l}^{(3)}(k)\right) \\
O_{l}^{(3)}(k)=k_{p} \\
O_{2}^{(3)}(k)=k_{i} \\
O_{3}^{(3)}(k)=k_{d}
\end{gathered}
$$

Thus, the function of activation which offers the association amongst individually neuron output and input within output layer is $g(x)$. The output layer yields are the $k_{p}, k_{i}$ and $k_{d}$ which are the parameters of PID. In view of the fact that the values cannot to be negative, the function of sigmoid that is non-negative is scrutinised as the function of activation within output layer. This is specified as follows in equation 25:

$$
g(x)=\frac{1}{2}(1+\tanh (x))=\frac{e^{x}}{e^{x}+e^{-x}}
$$

Accordingly, the projected NN can automatically tune the parameters of PID, and this can assist engineers through the means of lessening cost of time for system control process planning. Albeit, in process control that is model-based, modelling errors occur frequently and intensely enlarge the problem to precisely regulate the procedure. So, algorithm of on-line training is utilised to regulate weights of the network for lessening error $e_{y}$ of the system within back-propagation NN controller design.

\section{Scenario-Based Weight Update}

The error output system function in this algorithm is demarcated through the specified equation 26 as follows:

$$
E_{y}(k)=\frac{1}{2}(r(k)-y(k))^{2}=\frac{1}{2} e_{y}^{2}
$$

The model of NN training process should be implemented hitherto it can be set into usage. This process of training is recurrent pending the training data mean-square-error extend to the anticipated lower-limit. The process of training in the existing work is basically grounded upon the back propagation. The back propagation elementary knowledge is to regulate the weights of the neuron by means of utilising the algorithm of gradient descent on the function error in the process of iteration. Usually, individually weight adjustment as of the hidden layer in the direction of output layer can be conveyed in equation 27 as: 


$$
\Delta w_{l i}^{(3)}(k)=-\eta \frac{\partial E_{y}(k)}{\partial w_{l i}^{(3)}}
$$

A term of momentum is supplemented to the change of weight in the anticipated algorithm for the reason to evade the local minima, which is typically the recognised issue connected by the algorithm of backpropagation. This buttresses that the weight transforms the process of iteration and is even contingent not precisely upon the existing error; however, upon hitherto transformations. As revealed in Figure 8, individually weight adjustment as of the hidden layer, in the direction of output layer is altered grounded upon the function of output error system.

$$
\Delta w_{l i}^{(3)}(k)=-\eta \frac{\partial E_{y}(k)}{\partial w_{l i}^{(3)}}+\alpha \Delta w_{l i}^{(3)}(k-1)
$$

For $\alpha$ is the factor of momentum and $\eta$ is the rate of learning.

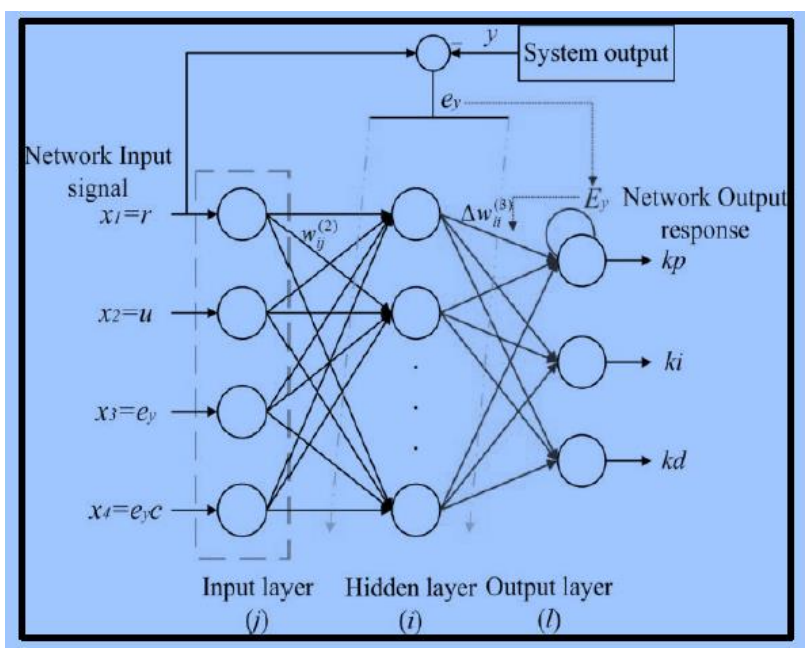

Figure 8. The hidden layer to output layer weight adjustment

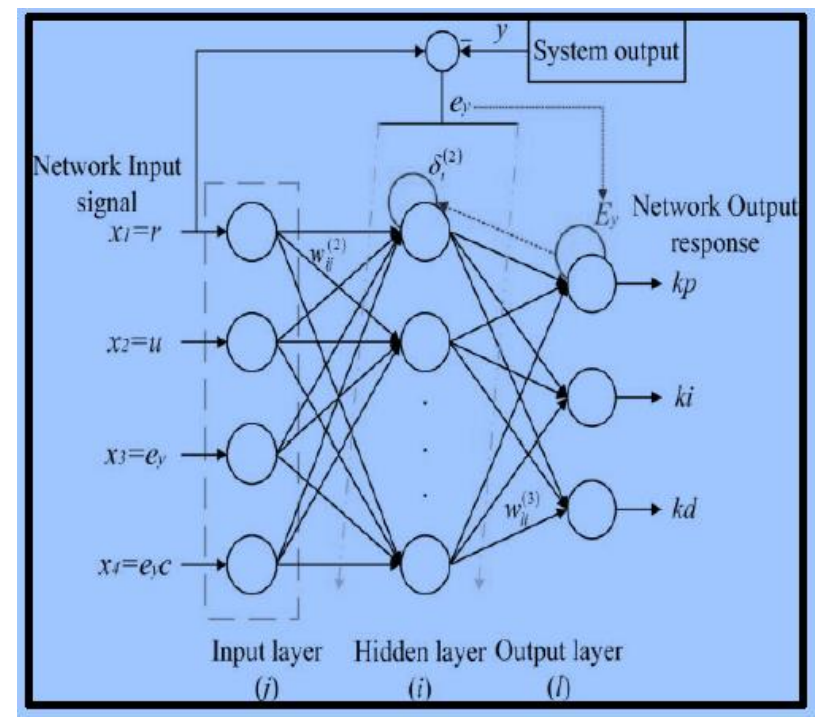

Figure 9. The hidden layer network error function 


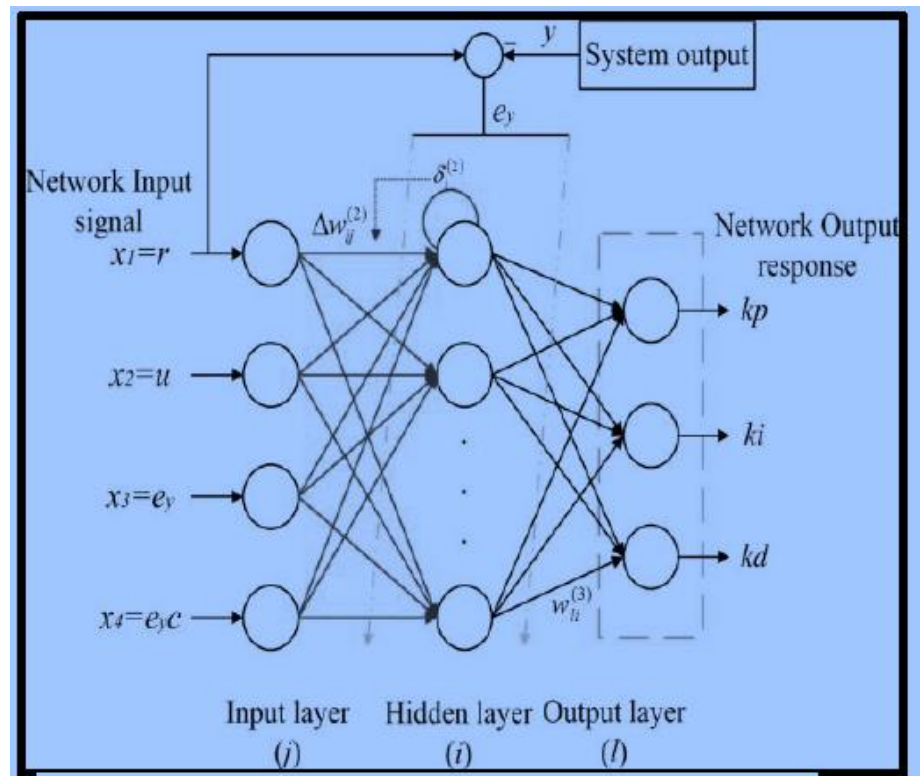

Figure 10. The input layer to hidden layer weight adjustment

Subsequently,

$$
\begin{gathered}
\frac{\partial E_{y}(k)}{\partial w_{l i}^{(3)}(k)}=\frac{\partial E_{y}(k)}{\partial y(k)} \cdot \frac{\partial y(k)}{\partial u(k)} \cdot \frac{\partial u(k)}{\partial O_{l}^{(3)}(k)} \cdot \frac{O_{l}^{(3)}(k)}{\partial \sin _{l}^{(3)}(k)} \cdot \frac{\partial n_{l}^{(3)}(k)}{\partial w_{l i}^{(3)}(k)} \\
\frac{\partial i_{l}^{(3)}(k)}{\partial w_{l i}^{(3)}(k)}=O_{l}^{(2)}(k)
\end{gathered}
$$

The subsequent equations are calculated through focussing upon equation 12 and individual neuron output within output layer:

$$
\begin{gathered}
\frac{\partial u(k)}{\partial o_{l}^{(3)}(k)}=e_{y}(k)-e_{y}(k-1) \\
\frac{\partial u(k)}{\partial O_{2}^{(3)}}=e_{y}(k) \\
\frac{\partial u(k)}{\partial o_{3}^{(3)}}=e_{y}(k)-2 e_{y}(k-1)+e_{y}(k-2)
\end{gathered}
$$

In output layer, the weight update of learning algorithm can be conveyed as:

$$
\begin{gathered}
w_{l i}^{(3)}(k+1)=w_{l i}^{(3)}(k)+\Delta w_{l i}^{(3)}(k) \\
\Delta w_{l i}^{(3)}(k)=\alpha \Delta w_{l i}^{(3)}(k-1)+\eta \delta_{l}^{(3)} O_{i}^{(2)}(k)
\end{gathered}
$$


As shown in Figure $9, \delta_{l}^{(3)}$ is the function error of hidden-layer network, which is required for weights adjustment of the input layer, in the direction of hidden layer.

Thus, $\delta_{l}^{(3)}$ is conveyed as:

$$
\delta_{l}^{(3)}=e_{y}(k) \cdot \frac{\partial y(k)}{\partial u(k)} \cdot \frac{\partial u(k)}{\partial o_{l}^{(3)}(k)} \cdot g^{\prime}\left(i n_{l}^{(3)}(k)\right)
$$

For $g(x)$, which is the first derivative is specified as follows:

$$
g^{\prime}(x)=g(x)(1-g(x))
$$

By way of utilising calculations that are similar and the hidden layer weight update - it is typically calculated grounded upon algorithm of gradient descent and the function of hidden layer error as illustrated in Figure 10. As follows, algorithm of learning can be conveyed as:

$$
\begin{gathered}
w_{i j}^{(2)}(k+1)=w_{i j}^{(2)}(k)+\Delta w_{i j}^{(2)}(k) \\
\Delta w_{i j}^{(2)}(k)=\alpha \Delta w_{i j}^{(2)}(k-1)+\eta \delta_{i}^{(2)} O_{j}^{(1)}(k) \\
\delta_{l}^{(2)}=f^{\prime}\left(i n_{i}^{(2)}(k)\right) \cdot \sum_{i=1}^{3} \delta_{l}^{(3)} w_{l i}^{(3)}(k)
\end{gathered}
$$

For $f(x)$, which is the first derivative is specified as follows:

$$
f^{\prime}(x)=\frac{\left(1-f^{2}(x)\right)}{2}
$$

Consequently, the $\mathrm{NN}$ weights are trained in the control process via the weights of backpropagation rule adjustment for the reason to acquire the optimum $k_{p}, k_{i}$ and $k_{d}$, which are the parameters of PID for the controller of PID. Thus, a suitable IAQ can be given through the designed system control. The backpropagation NN algorithm control process grounded upon PID can be synopsised in Table 6.

Table 6. Control process of backpropagation NN-PID

\begin{tabular}{|l|l|}
\hline \multicolumn{2}{|l|}{ Backpropagation NN - PID Process } \\
\hline (i) & $\begin{array}{l}\text { Adjust the momentum factor } \alpha \text { despite } k=1 \text {, learning rate } \eta \text { and } \\
\text { individual weight in the NN } w_{i j}^{(2)}(k) \text { and } w_{l i}^{(3)}(k)\end{array}$ \\
\hline (ii) & Assemble data $r(k)$ and $y(k)$, and analyse the $e_{y}$ system error \\
\hline (iii) & $\begin{array}{l}\text { Analyse each neuron input and output and obtain the } k_{p}, k_{i} \\
\text { and } k_{d} \text { parameters of PID }\end{array}$ \\
\hline
\end{tabular}


(iv) Analyse the output of PID controller

(v) Regulate individual neuron weight in the NN with the learning algorithm of backpropagation to apprehend the parameters $k_{p}, k_{i}$ and $k_{d}$ of PID self-adaptive regulation

\section{Results}

\subsection{Backpropagation Neural Network PID Control Simulation}

For the purpose of attaining and sustaining the appropriate level of IAQ $\left(\mathrm{CO}_{2}\right)$, backpropagation NN which is based upon PID is designed in this paper. The anticipated backpropagation NN which is based upon PID controller integrates the PID controller and a $\mathrm{NN}$ which is, in turn, applied to the algorithm of backpropagation. The design structure was fundamentally discussed in section 3. This controller structure comprises two key portions which are the PID control for IAQ and backpropagation NN for adjusting the PID controller parameters as stated by the existing conditions of the indoor environment. The IAQ can be well-controlled grounded upon the theoretical dialogue of the algorithm of the backpropagation NN which is based upon PID controller that possesses the subsequent capacities:

- NNs for ideal parameters of PID regulation to guarantee rapid disturbance recovery;

- algorithm of backpropagation for weights adjustment in NN to guarantee the system rapidly responds to change of the indoor environment;

- PID controller is appropriate for several object control as well as IAQ.

Upon the purpose to evaluate and discuss the proposed design of indoor environment control, the simulations are carried out in this section. Likewise, the results of the simulation are employed to designate the performance of the controller grounded upon some indexes such as the adaptability, stability, time constant, overshot and speed response. Subsequently, if the projected regulator can attain the selected control of the IAQ environment obligation, then it is grounded upon the controller's exhibition on the indexes mentioned. Therefore, simulating tests are applied towards conduct and the outcomes are examined to discuss the presentation together with the anticipated control approach in IAQ regulator. The precise modelling of the actual control object all through the simulation is the $\mathrm{CO}_{2}$ concentration in an observed indoor environment. The transfer function for the control of IAQ is presented in section 3 , however, minor alteration is done to the theoretical transfer function in order to basically make it further precise to the actual indoor environment. The $\mathrm{z}$-transform of the s-domain transfer function is taken in section 3. $y(z)$ is the output which is actually the indoor $\mathrm{CO}_{2}$ and is used as the transfer function:

$$
y(z)=\frac{\left(1 / V_{i}\right) z}{z-\exp \left(-1 / T_{i c o_{2}}\right)} a(z)
$$

For $a(z)$ is continuously changing time parameter and specified by $a(z)=1.4\left(1-0.9 e^{-0.3 z}\right)$.

The principle alteration is to improve a time changing parameter characterised to the 


\section{Macrothink}

transformation of the $\mathrm{CO}_{2}$ concentration of the indoor environment, vis-à-vis to the parameters that are unpredictable and uncertain. For instance, doors opening as a result of individuals leaving or entering the room can perhaps originate system disturbance.

\subsection{Utilisation of Step Input Test}

Accordingly, simulation is carried out through the step signal. Following numerous tests and setting the superlative preliminary factor of momentum and rate of learning. The $\alpha$ is 0.04 and $\eta$ is 0.28 . Also, the $\mathrm{NN}$ weights are set in the array [-0.5, 0.5] arbitrarily. The arbitrarily predetermined weights possibly will originate a control process that is slightly unbalanced; nonetheless, the algorithm of back-propagation is competent to rapidly answer indeterminate parameters and the $\mathrm{NN}$ weights are basically updated in comparatively quick period of time in order to guarantee the selected yield.

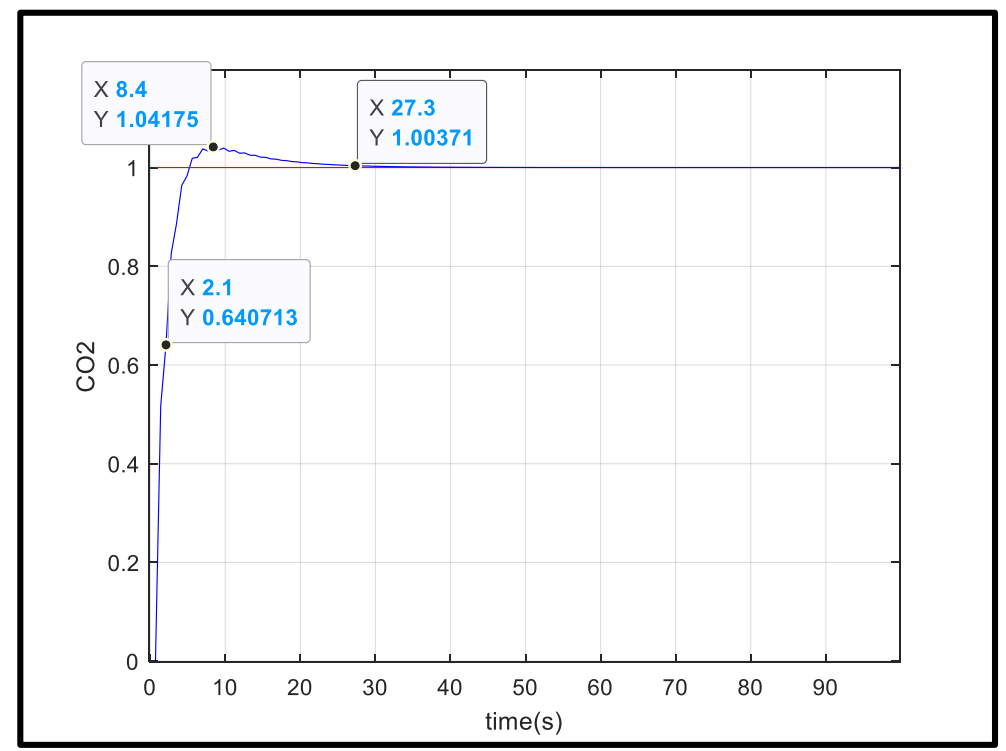

Figure 11. Response output to step input of the system

At the time zero, the step signal represented as $(r(k)=1)$ is presented. In Figure 11, the recommended control system output result of the simulation is offered. Also, the system appears to possess speedy increase together with insignificant overshot as revealed in Figure 11. It demonstrates that, $t_{s}$ is $27.3 \mathrm{~s}$ (settling time), $\tau$ is $2.1 \mathrm{~s}$ (constant time) and $\sigma$ is $4 \%$ (overshot maximum percentage). The unpredictability may possibly be produced through arbitrarily predetermined NN weight values vis-à-vis, not possessing substantial concerned control process basically at the response commencement, as the curve is speedily rising. Even though the overshot is still minute, it is fundamentally withdrawn to the set-point $-4 \%$ in the simulation test and the process of control is taken back to the definite steady state as revealed in the profile which is zero steady error. However, the steady error is basically zero for the reason that, the function of control object is calculated grounded upon a perfect model of the indoor environment. Thus, the error of the system usually occurs in actual control procedure. 


\section{Macrothink}

The output response of PID controller to the input step signal is offered in Figure 12. For the regulator calculated the yield (control command) for the system (command is conveyed to the device and transformed the IAQ). Therefore, in Figure 11, the results of the system output demonstrate that the controller is competent to attain the mandatory yield in order to guarantee a high-quality execution on control accuracy and speed.

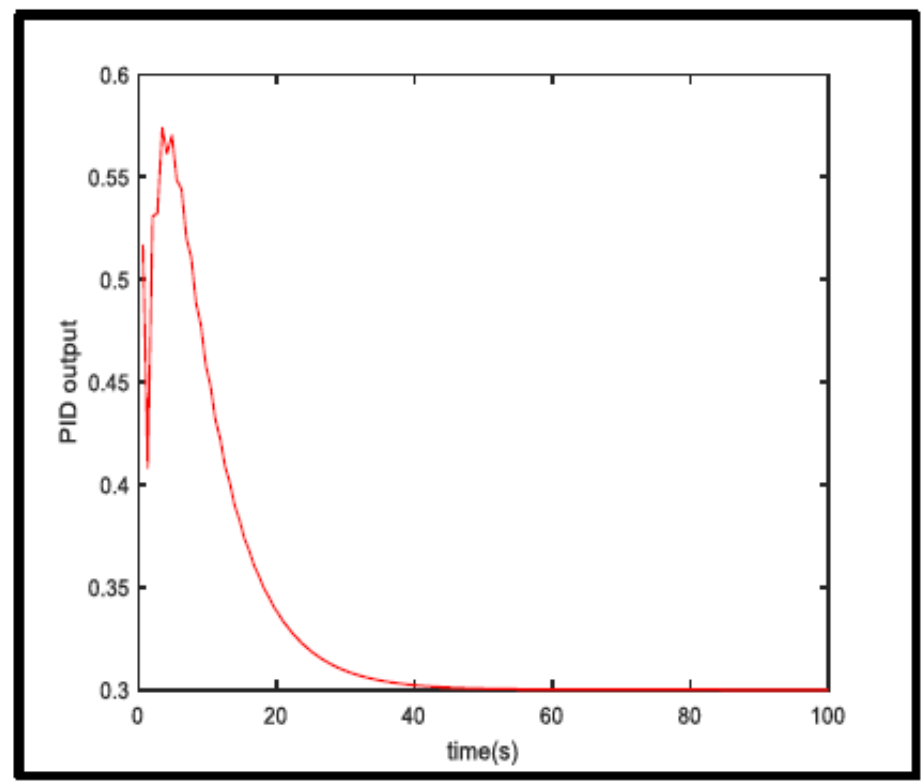

Figure 12. Response output to step input of PID

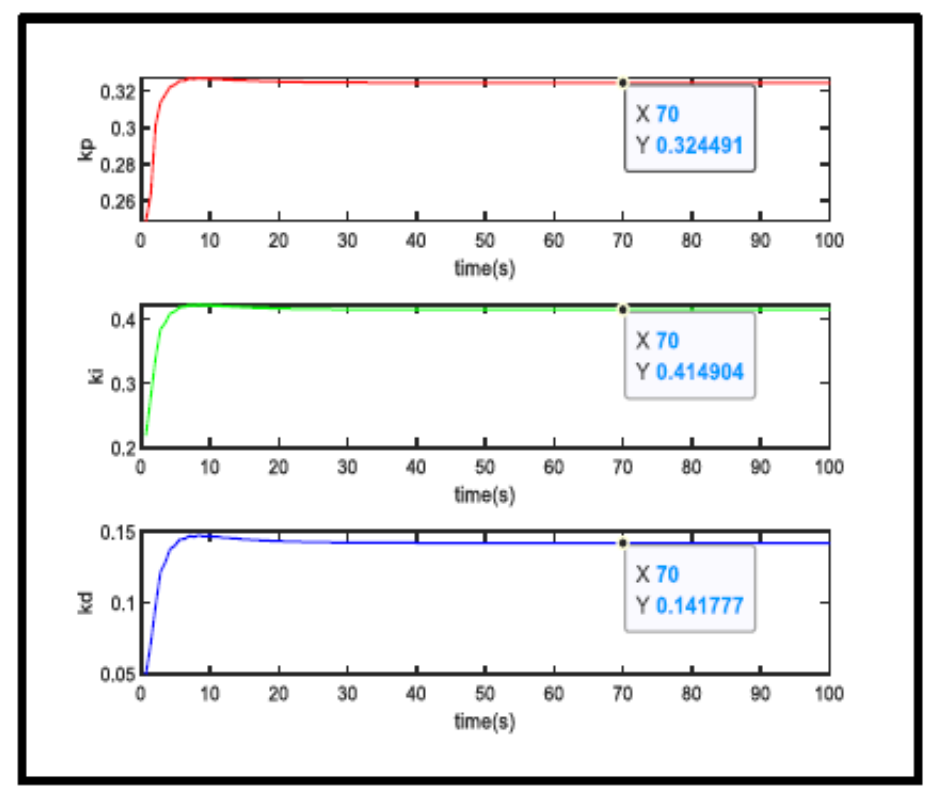

Figure 13. Parameters of PID auto-regulating

In Figure 13, the $k_{p}, k_{i}$ and $k_{d}$ parameters of the PID auto-tuning process can be seen, and the parameters of PID are modified via the $\mathrm{NN}$ all through the process of control. Also, in Figure 


\section{Macrothink}

11, the results of the system yield show appropriate control execution. As a result, this illustrates that suitable parameter of PID can possibly be attained by means of utilising the algorithm online training which is grounded upon the control structure of NN. Likewise, the parameters of PID control value kept regulating, in order to enhance the system control execution until it arrives a state of steadiness. The parameters demonstrate that, $k_{p}$ is $0.32, k_{i}$ is 0.41 and $k_{d}$ is 0.14 , and they remain steady when the system arrives the state of steadiness.

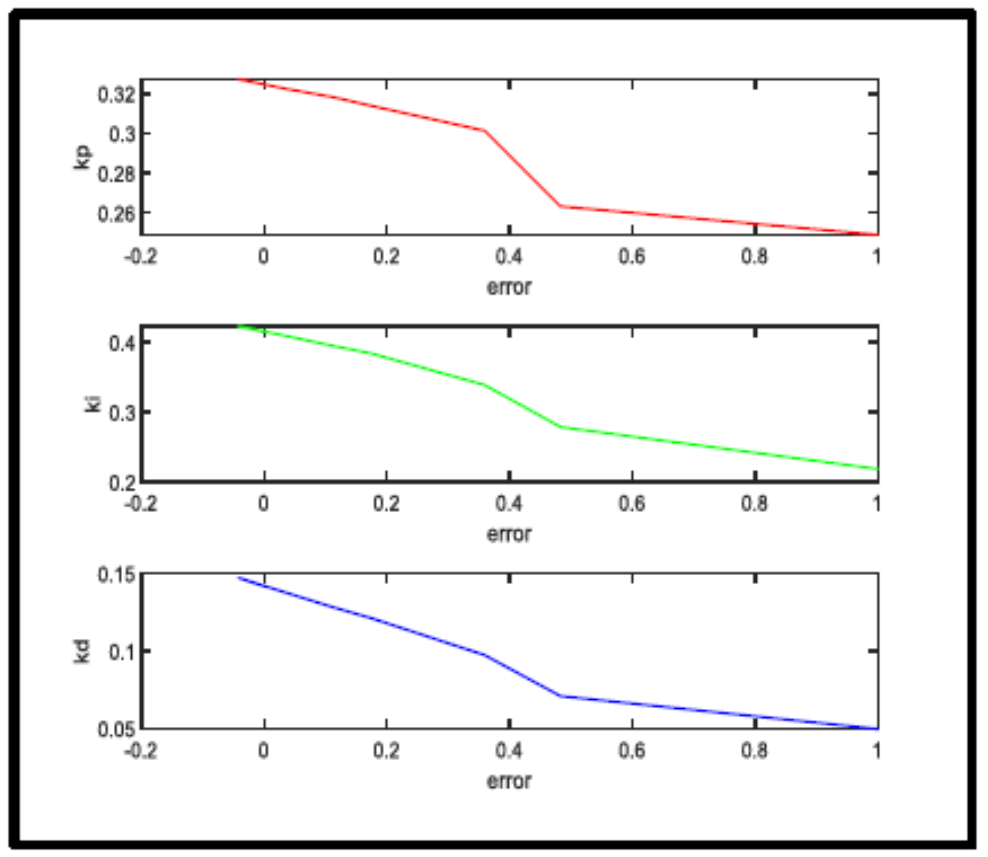

Figure 14. Association amongst parameters of PID and the system error

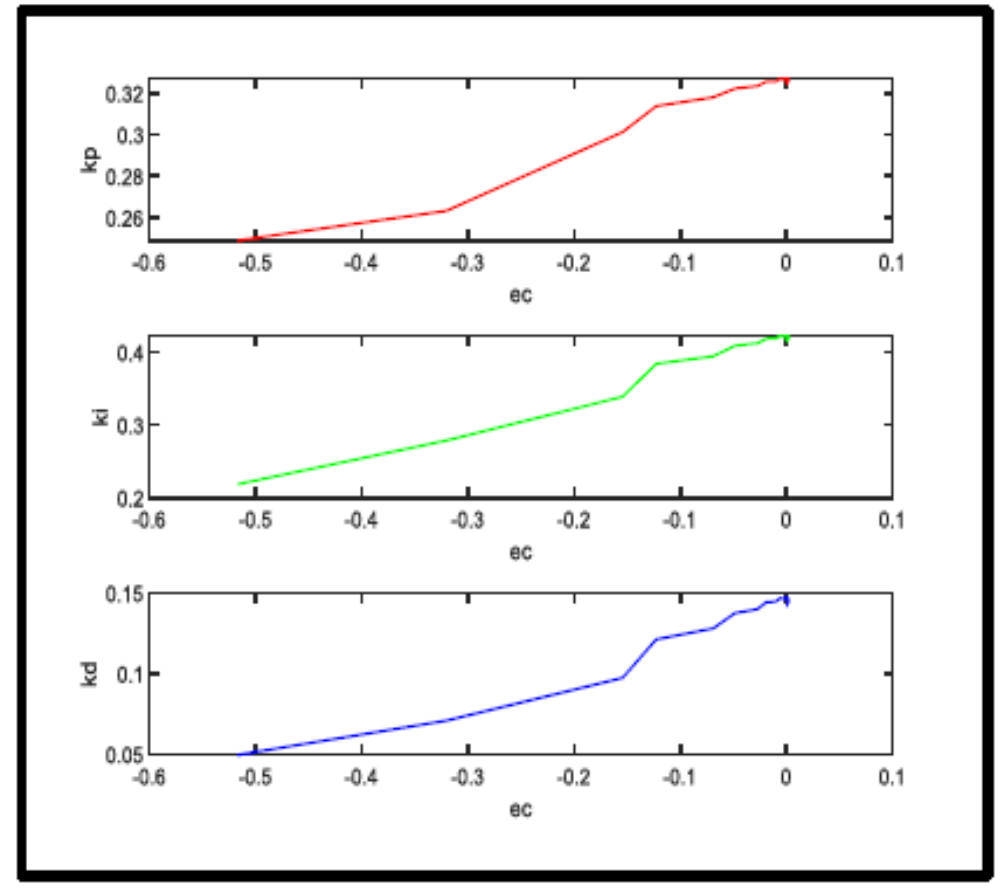

Figure 15. Parameters of PID response to ec 
The parameters of the PID are controlled grounded upon the following variables namely, system output $(u)$, PID controller error output $(u)$, change of system error output $(e c)$ and the system error output $(e)$. For it may be realised that solitary $e c$ value or $u$ value can sometimes signify numerous parameters of PID. However, this reveals that the incorrect parameters of the PID can be formed should basically one input is utilised to the NN. Hence, by means of the variables possessing four inputs, the backpropagation $\mathrm{NN}$ algorithm design can calculate and subsequently offer the best optimised control execution of the $k_{p}, k_{i}$ and $k_{d}$ parameters.
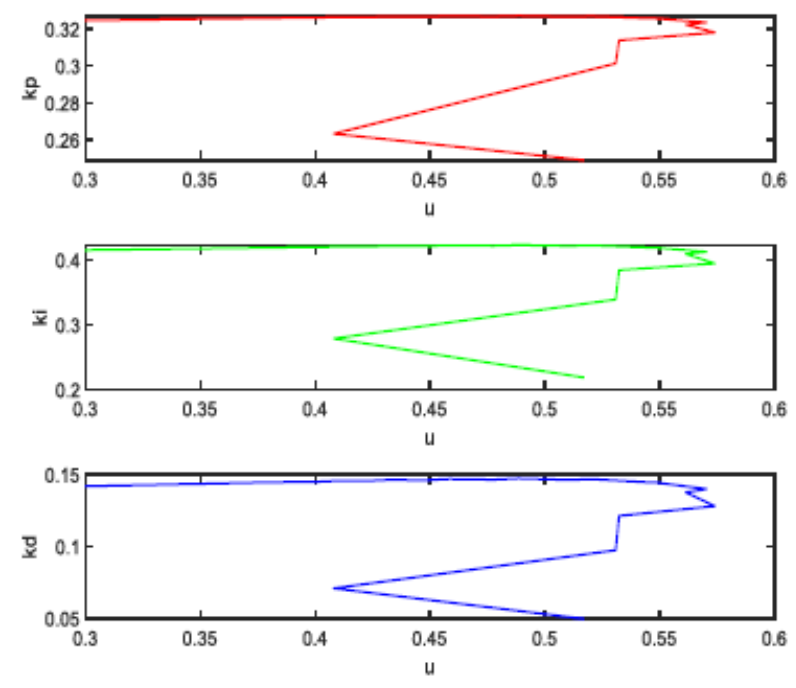

Figure 16. Parameters of PID response to PID output

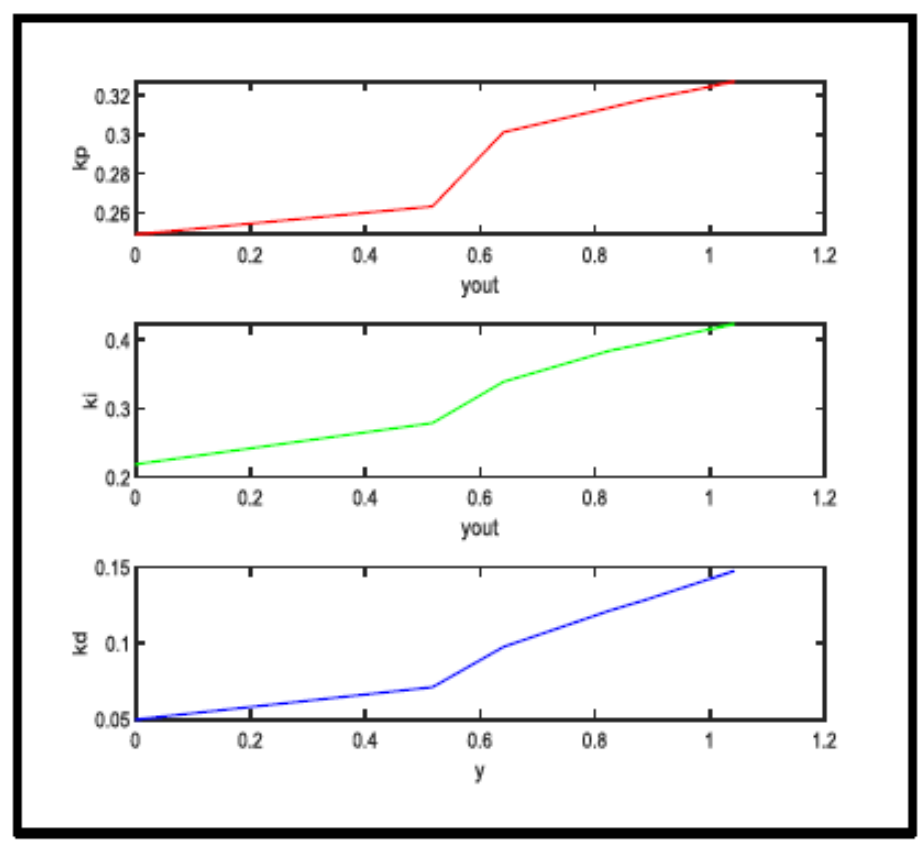

Figure 17. Parameters of PID response to the system output 


\subsection{Control Execution of Backpropagation Neural Network PID}

Changing model of the indoor $\mathrm{CO}_{2}$ concentration simulation is performed for the reason to appraise the control performance of backpropagation NN-PID. Therefore, dual input reference namely, sine and step signal are utilised to the process of control. For it is revealed by means of the simulating tests that, the method of backpropagation can offer appropriate parameters for the controller of PID and then, the chosen system yield can be accomplished. As a result, the recommended controller possesses appropriate execution on tuning parameters of PID with adaptability and stability, managing with the time changing parameter, small steady error, small overshot, settling speed and speedy rising.

In addition, the advantages brand the projected controller appropriate for regulating IAQ and proficient to resolve the key indoor $\mathrm{CO}_{2}$ control difficulties as well as disturbances, time delay, and mismeasurement existence. For instance, further individuals unexpectedly arrive at the indoor environment, meanwhile $\mathrm{CO}_{2}$ is extremely responsive to the level of habitation. Therefore, the projected backpropagation NN-PID control approach ascertained the suitable control execution for IAQ environment.

\section{Conclusion}

Indoor environment quality has fundamentally influenced inhabitants' wellbeing, individuals' efficiency and comfort feelings. Thus, significant factor, for example, the was examined and must be properly controlled for growing request of expectation for everyday comforts. In any case, significant troubles exist as presented in the table below that basically cut-off the control innovations development for the control of indoor environment quality.

\begin{tabular}{|l|l|}
\hline \multicolumn{2}{|l|}{ Control Technology Restriction } \\
\hline (i) & $\begin{array}{l}\text { Difficulty to use suitable ideal guides to pursuit for the best set point(s) and to forecast } \\
\text { response of the system. }\end{array}$ \\
\hline (ii) & Multifaceted air-conditioning control are tough to be examined. \\
\hline (iii) & The delay of time \\
\hline (iv) & $\begin{array}{l}\text { In both IAQ and thermal comfort control, disturbances constantly occur in the process } \\
\text { control. For example, individuals entering the room can increase the } \mathrm{CO}_{2} \text { concentration } \\
\text { while opening door or window might create the variation of indoor temperature. }\end{array}$ \\
\hline (v) & The system lag-behind response to the change of indoor environment. \\
\hline (vi) & $\begin{array}{l}\text { One of the main difficulties of IAQ is control signal value of mismeasurement } \\
\text { occurrence }\end{array}$ \\
\hline (vii) & $\begin{array}{l}\text { Since the control signals occasionally relies on one another, it can create the state of } \\
\text { unsteady performance control. }\end{array}$ \\
\hline
\end{tabular}

Upon the purpose to resolve these difficulties, this paper evidently designed and consolidated the backpropagation NN-PID smart/intelligent controllers for controlling IAQ $\left(\mathrm{CO}_{2}\right)$. The controller designs which incorporate the algorithms and structures control are thoroughly examined. For it synopsises the individual controller design and hypothetically examines their possible control benefits. 
The indoor environment control has several problems as described in the literature and backpropagation NN based upon PID is designed in this paper to resolve the problems. The IAQ control difficulties can be finalised as follows:

- occurrence of mismeasurement;

- delay of time;

- lag-behind system response: the change of indoor environment.

For the purpose of attaining and sustaining the appropriate level of IAQ $\left(\mathrm{CO}_{2}\right)$, backpropagation NN based upon PID is designed in this paper. The anticipated backpropagation NN based upon PID controller integrate the PID controller and a NN which is applied to the algorithm of back-propagation. This controller structure comprises two key portions which are the PID control for IAQ and backpropagation NN for adjusting the PID controller parameters as stated by the existing conditions of the indoor environment. The IAQ can be well-controlled grounded upon the theoretical dialogue of the algorithm of the backpropagation NN which is based upon PID controller that possesses the subsequent capacities:

- NN for ideal parameters of PID regulation to guarantee rapid disturbance recovery;

- algorithm of backpropagation for weights adjustment in NN to guarantee the system rapidly answer to change of the indoor environment;

- PID controller is appropriate for several object control as well as IAQ.

Accordingly, the indoor $\mathrm{CO}_{2}$ concentration simulation changing model is accomplished in this paper to designate the performance of backpropagation NN-PID control. Likewise, it is revealed by means of simulations that the backpropagation NN method can offer appropriate PID parameters and, in turn, enables the selected system output to be attained. As a result, the projected controller possesses suitable control execution in terms of the adaptability, stability, managing with the time changing parameter, small steady error, small overshot, settling speed, speedy rising and online training of the regulator as requested. Consequently, these brand the projected controller appropriate for IAQ control and proficient to solve the main difficulties of indoor environment $\mathrm{CO}_{2}$ as deliberated upon in section 3. Meanwhile, the deliberation of the execution indexes demonstrated that PID controller is fundamentally appropriate for numerous control item as well as the IAQ. Likewise, the NNs are suitable for ideal parameters of PID controller tuning that, in turn, guarantee controller's steadiness, whereas back-propagation algorithm is also appropriate for weights adjustments in $\mathrm{NN}$ which, in turn, guarantees that the system speedily respond to sustainable indoor environment transformation. Therefore, there is development, steadiness and productivity of the system for sustainable solutions to the worlds indoor health problems.

\section{References}

ACGIH. (2017). Carbon dioxide Threshold Limit Values for Chemical Substances and Physical Agents and Biological Exposure Indices with 7th Edition Documentation, American Conference of Governmental Industrial Hygienists, Cincinnati, $\mathrm{OH}$.

Aftab, M., Chau, C., \& Armstrong, P. (2013). Smart air conditioning control by wireless 
sensors: an online optimization approach. In proceedings of the fourth international conference on future energy systems, e-Energy, New York, NY, USA.

https://doi.org/10.1145/2487166.2487192

Ahmad, M. W., Mourshed, M., \& Yuce, B. (2016). Computational intelligence techniques for HVAC systems: A review. Build. Simul., 9, 359-398.

https://doi.org/10.1007/s12273-016-0285-4

Alcala, R., Benitez, J. M., Casillas, J., Cordon, O., \& Perez, R. (2003). Fuzzy control of HVAC systems optimized by genetic algorithms. Applied Intelligence, 18, 155-177. https://doi.org/10.1023/A:1021986309149

Allen, J. G., MacNaughton, P., Satish, U., Santanam, S., Vallarino, J., \& Spengler, J. D. (2016). Associations of cognitive function scores with carbon dioxide, ventilation, and volatile organic compound exposures in office workers: a controlled exposure study of green and conventional office environments. Health Perspect., 124, 805-812.

https://doi.org/10.1289/ehp.1510037

Altinten, A., Erdogan, H., Hapoglu, F., Aliev, F., \& Alpbaz, M. (2006). Application of fuzzy control method with genetic algorithm to a polymerization reactor are constant set point. Chemical engineering research and design, 84(A11), 1012-1018.

https://doi.org/10.1205/cherd06027

Alvarez, J. M., \& Salzmann, M. (2016). Learning the Number of Neurons in Deep Networks. 30th Conference on Neural Information Processing Systems (NIPS 2016), Barcelona, Spain.

Argiriou, A., Bellas-Velidis, I., Kummert, M., \& André, P. (2004). A neural network controller for hydronic heating systems of solar buildings. Neural networks: the official journal of the International Neural Network Society, 17, 427-40.

https://doi.org/10.1016/j.neunet.2003.07.001

Ari, S., Cosden, I. A., Khalifa, H. E., Dannenhoffer, J. F., Wilcoxen, P., \& Isik, C. (2005). Constrained fuzzy logic approximation for indoor comfort and energy optimisation. In: Annual conference of the North American Fuzzy Information Processing Society-NAFIPS. pp. 500-504. https://doi.org/10.1109/NAFIPS.2006.365493

ASHRAE 62.1. (2019). Ventilation for Acceptable Indoor Air Quality. [Online] Available: www.ashrae.org/technical-resources/standards-and-guidelines/read-only-versions-of-ashrae-st andards

Atari, D. O., Luginaah, I. N., \& Fung, K. (2009). The relationship between odour annoyance scores and modelled ambient air pollution in Sarnia, "Chemical Valley", Ontario. International journal of environmental research and public health, 6(10), 2655-2675. https://doi.org/10.3390/ijerph6102655

Beama. (2016). IAQ Question time; My Health My Home. [Online] Available:

https://www.hvnplus.co.uk/download?ac=3034114

Behrooz, F., Mariun, N., Marhaban, M. H., Mohd Radzi, M. A., \& Ramli, A. R. (2018). 


\section{Macrothink}

Environmental Management and Sustainable Development

ISSN 2164-7682 2022, Vol. 11, No. 1

Review of Control Techniques for HVAC Systems-Nonlinearity Approaches Based on Fuzzy Cognitive Maps. Energies, 11, 495. https://doi.org/10.3390/en11030495

Blanes-Vidal, V., Bælum, J., \& Schwartz, J. (2014). Respiratory and sensory irritation symptoms among residents exposed to low-to-moderate air pollution from biodegradable wastes. J Expo Sci Environ Epidemiol, 24, 388-397. https://doi.org/10.1038/jes.2014.20

Bonala S. Y. (2009). A Study on Neural Network Based System Identification with Application to Heating, Ventilating and Air Conditioning System. National Institute of Technology, Rourkela.

Bosque, G., del Campo, I., \& Echanobe, J. (2014). Fuzzy systems, neural networks and neuro-fuzzy systems: A vision on their hardware implementation and platforms over two decades. Engineering Applications of Artificial Intelligence, 32.

https://doi.org/10.1016/j.engappai.2014.02.008

Brook, R. D., Rajagopalan, S., PopeIII, C. A., Brook, J. R., Bhatnagar, A., Diez-Roux, A. V., ... Mittleman, M. A. (2010). Particulate matter air pollution and cardiovascular disease: An updateto the scientific statement from the american heart association. Circulation, 121, 2331-2378. https://doi.org/10.1161/CIR.0b013e3181dbece1

Campbell, S. D. (2013). Sustainable Development and Social Justice: Conflicting Urgencies and the Search for Common Ground in Urban and Regional Planning. Michigan Journal of Sustainability, 1, 75-91. https://doi.org/10.3998/mjs.12333712.0001.007

Capelli, L., Bax, C., Diaz, C., Izquierdo, C., Arias, R., \& Seoane, N. S. (2019). Review on odour pollution, odour measurement, abatement techniques. D-NOSES (Distributed Network for Odour Sensing, Empowerment and Sustainability), Ares.

Carreiro-Martins, P., Papoila, A. L., Caires, I., Azevedo, S., Cano, M. M., ... Neuparth, N. (2016). Effect of indoor air quality of day care centers in children with different predisposition for asthma Pediatr. Allergy Immunol., 27, 299-306.

https://doi.org/10.1111/pai.12521

Carreiro-Martins, P., Viegas, J., Papoila, A. L., Aelenei, D., Caires, I., ... Neuparth, N. (2014). $\mathrm{CO}_{2}$ concentration in day care centres is related to wheezing in attending children. Eur $J$ Pediatr, 173, 1041-1049. https://doi.org/10.1007/s00431-014-2288-4

Chakraborty, M. (2012). Artificial Neural Network for Performance Modeling and Optimization of CMOS Analog Circuits. International Journal of Computer Applications, 58(18). https://doi.org/10.5120/9380-3731

Colom, R., Karama, S., Jung, R. E., \& Haier, R. J. (2010). Human intelligence and brain networks. Dialogues in clinical neuroscience, 12(4), 489-501.

https://doi.org/10.31887/DCNS.2010.12.4/rcolom

Dalipi, F., Yildirim, Yayilgan, S. Y., \& Gebremedhin, A. (2016). Data-Driven Machine-Learning Model in District Heating System for Heat Load Prediction: A Comparison Study. Applied Computational Intelligence and Soft Computing, 11. 
https://doi.org/10.1155/2016/3403150

De Maity, R. R., \& Mudi, R. K. (2015). Fuzzy Rule-Based Adaptive Proportional Derivative Controller. In S. Satapathy, B. Biswal, S. Udgata \& J. Mandal (Eds.), Proceedings of the 3rd International Conference on Frontiers of Intelligent Computing: Theory and Applications (FICTA) 2014. Springer, Cham. https://doi.org/10.1007/978-3-319-11933-5_22

De, S., Kaiadi, M., Fast, M., \& Assadi, M. (2007). Development of an artificial neural network model for the steam process of a coal biomass cofired combined heat and power (CHP) plant in Sweden. Energy, 32, 2099-2109. https://doi.org/10.1016/j.energy.2007.04.008

Devabhaktuni, V. K., Yagoub, M., Fang, Y., Xu, J., \& Zhang, Q. J. (2001). Neural networks for microwave modelling: Model development issues and nonlinear modelling techniques. Int. J. RF Microwave Computer-Aided Eng., 11, 4-21.

https://doi.org/10.1002/1099-047X(200101)11:1<4::AID-MMCE2>3.0.CO;2-I

Ding, X., Devabhaktuni, V., Chattaraj, B., Yagoub, M., Deo, M., Xu, J., \& Zhang, Q. (2004). Neural-Network Approaches to Electromagnetic-Based Modeling of Passive Components and Their Applications to High-Frequency and High-Speed Nonlinear Circuit Optimization. Microwave Theory and Techniques, IEEE Transactions on, 52. 436-449.

https://doi.org/10.1109/TMTT.2003.820889

Doroshenko, A. (2017). Problems of modelling Proportional-Integral-Derivative controller in automated control systems. MATEC Web of Conferences, 112. 05013.

https://doi.org/10.1051/matecconf/201711205013

EC. (2020). Framework for health-based ventilation guidelines in Europe. EUROPEAN Collaborative Action Urban Air, Indoor Environment and Human Exposure. Environment and Quality of Life, Report No 30.

EPA. (2018). Indoor Air Quality. What are the trends in indoor air quality and their effects on human health?. [Online] Available:

https://www.epa.gov/report-environment/indoor-air-quality

Esfandyari, M., Fanaei, M. A., \& Zohreie, H. (2013). Adaptive fuzzy tuning of PID controllers. Neural Comput \& Applic, 23, 19-28. https://doi.org/10.1007/s00521-012-1215-8

Ezraty, B., Chabalier, M., Ducret, A., Maisonneuve, E., \& Dukan, S. (2011). $\mathrm{CO}_{2}$ exacerbates oxygen toxicity. EMBO Reports, 12, 321-326. https://doi.org/10.1038/embor.2011.7

Ferreira, A. M., \& Cardoso, M. (2014). Indoor air quality and health in schools. J Bras Pneumol, 40(3), 259-268. https://doi.org/10.1590/S1806-37132014000300009

Gao, C., Kuklane, K., Wang, F., \& Holmér I. (2012). Personal cooling with phase change materials to improve thermal comfort from a heat wave perspective. Indoor Air, 22, 523-530. https://doi.org/10.1111/j.1600-0668.2012.00778.x

Ghadi, F., Mariun, N., Marhaban, M. H., Mohd Radzi, M. A., \& Ramli, A. R. (2018). Review of Control Techniques for HVAC Systems-Nonlinearity Approaches Based on Fuzzy Cognitive 
Maps.

Ghadi, Y. Y., Rasul, M. M. G., \& Khan, M. K. K. (2014). Recent Developments of Advanced Fuzzy Logic Controllers Used in Smart Buildings in Subtropical Climate. Energy Procedia, 61, 1021-1024. https://doi.org/10.1016/j.egypro.2014.11.1015

Girard, M., Girard, A., Suppin, A., \& Bartsch, S. (2016): The scentscape: An integrative framework describing scents in services capes. Journal of Business Market Management, 9(1), 597-622. [Online] Available: http://nbn-resolving.de/urn:nbn:de:0114-jbm-v9i1.1547

Gomes, H. M. (2012). Fuzzy logic for structural system control. Latin American Journal of Solids and Structures, 9, 111-129. https://doi.org/10.1590/S1679-78252012000100006

Guo, Y., Liu, F., Lu, Y., Mao, Z., Lu, H., Wu, Y., Chu, Y., Yu, L., Liu, Y., Ren, M., Li, N., Chen, X., \& Xiang, H. (2016). Factors Affecting Parent's Perception on Air Quality-From the Individual to the Community Level. International journal of environmental research and public health, 13(5), 493. https://doi.org/10.3390/ijerph13050493

Hamanaka, R. B., \& Mutlu, G. M. (2018). Particulate matter air pollution: Eects on the cardiovascular system. Front. Endocrinol., 9, 680.

Hassan, M. Y., \& Kothapalli, G. (2010). Comparison between Neural Network based PI and PID controllers. 7th International Multi- Conference on Systems, Signals and Devices. pp. 1-6. https://doi.org/10.1109/SSD.2010.5585598

Hoenen, M., Wolf, O. T., \& Pause, B. M. (2017). The Impact of Stress on Odor Perception. Perception, 46(3-4), 366-376. https://doi.org/10.1177/0301006616688707

HSDB. (2015). Bethesda (MD): U.S. National Library of Medicine Carbon dioxide Hazardous Substances Data Bank Number: 516. [Online] Available:

https://www.nlm.nih.gov/toxnet/index.html

Jaen-Cuellar, A. Y., de J. Romero-Troncoso, R., Morales-Velazquez, L., \& Osornio-Rios, R. A. (2013). PID-Controller Tuning Optimization with Genetic Algorithms in Servo Systems. International Journal of Advanced Robotic Systems. https://doi.org/10.5772/56697.

Kabrein, H., Yusof, M. Z. M., Hariri, A., Leman, A. M., \& Afandi, A. (2017). Improving indoor air quality and thermal comfort in office building by using combination filters. IOP Conference Series: Materials Science and Engineering, 243, 012052.

https://doi.org/10.1088/1757-899X/243/1/012052

Kajtár, L., \& Herczeg, L. (2012). Influence of carbon-dioxide concentration on human well-being and intensity of mental work. IDÖJÁRÁS, 116, 145-169.

Kalogirou, S. A. (2006). Artificial neural networks in energy applications in buildings. International Journal of Low Carbon Technologies, 1(3). https://doi.org/10.1093/ijlct/1.3.201

Kim, C. H., Lee, S. E., Lee, K. H., \& Kim, K. S. (2019). Detailed Comparison of the Operational Characteristics of Energy-Conserving HVAC Systems during the Cooling Season. Energies, 12, 4160. https://doi.org/10.3390/en12214160 
Kjellstrom, T., Holmer, I., and Lemke, B. (2009). Workplace heat stress, health and productivity an increasing challenge for low-and middle-income countries during climate change. Glob. Health Action. https://doi.org/10.3402/gha.v2i0.2047

Kontaris, I., East, B. S., \& Wilson, D. A. (2020). Behavioral and Neurobiological Convergence of Odor, Mood and Emotion: A Review. Frontiers in behavioral neuroscience, 14, 35. https://doi.org/10.3389/fnbeh.2020.00035

Kukadia V., \& Upton, S. (2019). Ensuring good indoor air quality in buildings. [Online] Available: https://www.bregroup.com/bretrust/wp-content/uploads/sites/12/2019/03/Ensuring -Good-IAQ-in-Buildings-Trust-report_compressed-2.pdf

Kurian, C. P., Kuriachan, S., Bhat, J., \& Aithal, R. S. (2005). An adaptive neuro-fuzzy model for the prediction and control of light in integrated lighting schemes. Lighting Research and Technology, 37, 343-352. https://doi.org/10.1191/1365782805li150oa

Lenzer, B., Rupprecht, M., \& Hoffmann, C. (2020). Health effects of heating, ventilation and air conditioning on hospital patients: a scoping review. BMC Public Health, 20, 1287.

https://doi.org/10.1186/s12889-020-09358-1

Leung, Y. C. (2015). Outdoor-indoor air pollution in urban environment: challenges and opportunity. Frontiers in Environmental Science, 2, 69.

https://doi.org/10.3389/fenvs.2014.00069

Liu, Y., Yan, H., \& Lam, J. C. (2014). Thermal comfort and building energy consumption implications-A review, Applied Energy, 115, 164-173.

https://doi.org/10.1016/j.apenergy.2013.10.062

MacNaughton, P., Spengler, J., Vallarino, J., Santanam, S., Satish, U., \& Allen J. (2016). Environmental perceptions and health before and after relocation to a green building. Build. Environ., 104, 138-144. https://doi.org/10.1016/j.buildenv.2016.05.011

Manisalidis, I., Stavropoulou, E., Stavropoulos, A., \& Bezirtzoglou, E. (2020). Environmental and Health Impacts of Air Pollution: A Review. Frontiers in public health, 8, 14. https://doi.org/10.3389/fpubh.2020.00014

Marvuglia, A., Messineo, A., \& Nicolosi, G. (2014). Coupling a neural network temperature predictor and a fuzzy logic controller to perform thermal comfort regulation in an office building. Building and Environment, 72, 287-299.

https://doi.org/10.1016/j.buildenv.2013.10.020

Mauthner, F., \& Weiss, W. (2014). Solar Heat Worldwide Markets and Contribution to the Energy Supply. Gleisdorf, Austria: IEA Solar Heating \& Cooling Programme. pp. 61. https://doi.org/10.18777/ieashc-shw-2014-0001

Montero-Montoya, R., López-Vargas, R., \& Arellano-Aguilar, O. (2018). Volatile Organic Compounds in Air: Sources, Distribution, Exposure and Associated Illnesses in Children. Annals of global health, 84(2), 225-238. https://doi.org/10.29024/aogh.910 
Moon, J. W., \& Kim, J. J. (2010). ANN-based thermal control models for residential buildings. Building and Environment, 45, 1612-1625.

https://doi.org/10.1016/j.buildenv.2010.01.009

Morel, N., Bauer, M., El-Khoury, M., \& Krauss, J. (2001). Neurobat, a predictive and adaptive heating control system using artificial neural networks. International Journal of Solar Energy, 21, 161-201. https://doi.org/10.1080/01425910108914370

Mossolly, M., Ghali, K., \& Ghaddar, N. (2009). Optimal control strategy for a multi-zone air conditioning system using genetic algorithm. Energy, 34, 58-66.

https://doi.org/10.1016/j.energy.2008.10.001

Moyo, V. (2014). The generalization ability of Artificial Neural Networks in forecasting TCP/IP network traffic trends. University of fort hart. https://doi.org/10.5120/19885-1902

National Institute for Occupational Safety and Health. (2014). NIOSH. Criteria for a Recommended Standard: Occupational Exposure to Carbon Dioxide. [Online] Available: https://www.cdc.gov/niosh/docs/76-194/default.html

Oltra, C., \& Sala, R. (2014). A Review of the Social Research on Public Perception and Engagement Practices in Urban Air Pollution. Air Pollution; Risk Assessment; Public Information; Air Quality; Environmental Protection; Data Compilation.

Omanga, E., Ulmer, L., \& Berhane, Z. (2014). Industrial air pollution in rural Kenya: community awareness, risk perception and associations between risk variables. BMC Public Health, 14, 377. https://doi.org/10.1186/1471-2458-14-377

Oye, T. T., Goh, K., Gupta, N., \& Oye, T. K. (2020d). Development of Optimized Smart Indoor Control for Renewable Air-Conditioning. 2020 9th International Conference on Renewable Energy Research and Application (ICRERA), IEEE Xplore, Glasgow, United Kingdom. pp. 175-179. https://doi.org/10.1109/ICRERA49962.2020.9242846

Oye, T. T., Goh, K., Gupta, N., \& Oye, T. K. (2020a). Assessment of Renewable Air-Conditioning Using Economic Feasibility Procedures. International Journal of Innovative Science and Research Technology, 5(3), 1375-1381.

Oye, T. T., Gupta, N., Goh, K., \& Oye, T. K. (2020c). A Feasibility Study for the Development of Renewable Air-Conditioning for Different Climatic Conditions. Journal of Environmental Management and Sustainable Development, 9(3), 87-109, https://doi.org/10.5296/emsd.v9i3.17459

Oye, T. T., Gupta, N., Goh, K., \& Oye, T. K. (2020b). Theoretical Assessment of Sustainability Principles for Renewable Smart Air-Conditioning. Journal of Environmental Management and Sustainable Development, 9(3), 18-46.

https://doi.org/10.5296/emsd.v9i3.16953

Oye, T. T., Gupta, N., Goh, K., \& Oye, T. K. (2021). Air-Conditioning and the Transmission of COVID-19 in Indoor Environment. Journal of Environmental Management and Sustainable Development, 10(3), 18-46. https://doi.org/10.5296/emsd.v10i3.18461 


\section{Macrothink}

Environmental Management and Sustainable Development

ISSN 2164-7682

2022, Vol. 11, No. 1

Persily, A., \& de Jonge, L. (2017). Carbon dioxide generation rates for building occupants. Indoor air, 27(5), 868-879. https://doi.org/10.1111/ina.12383

Popoola, O. (2016). Modelling of Residential Lighting Load Profile Using Adaptive Neuro Fuzzy Inference System (ANFIS). International Journal of Green Energy, 13.

https://doi.org/10.1080/15435075.2016.1206013

Rami, A., \& Al-Jarrah, M. A. (2013). Developed adaptive neuro-fuzzy algorithm to control air conditioning system at different pressures. International Journal of Engineering, Science and Technology, 5(4), 43-59. https://doi.org/10.4314/ijest.v5i4.5

Scotton, L. F. (2012). Modeling and Identification for HVAC Systems. KTH Royal Institute of Technology.

Settimo, G., Manigrasso, M., \& Avino, P. (2020). Indoor Air Quality: A Focus on the European Legislation and State-of-the-Art Research in Italy. Atmosphere, 11, 370.

https://doi.org/10.3390/atmos11040370

Sibo Y., Ting, T. O., Man, K. L., \& Guan, S. (2013). Investigation of Neural Networks for Function Approximation. Procedia Computer Science, 17, 586-594.

https://doi.org/10.1016/j.procs.2013.05.076

Spence, C. (2020). Using Ambient Scent to Enhance Well-Being in the Multisensory Built Environment. Frontiers in Psychology, 11, 3140. https://doi.org/10.3389/fpsyg.2020.598859

Steinemann, A. (2017). Ten questions concerning air fresheners and indoor built environments. Building and Environment, 111, 279-284.

https://doi.org/10.1016/j.buildenv.2016.11.009

Tang, X., Misztal, P. K., Nazaro, W. W., \& Goldstein, A. H. (2015). Siloxanes are the most abundant volatile organic compound emitted from engineering students in a classroom. Environ. Sci. Technol. Lett, 2, 303-307. https://doi.org/10.1021/acs.estlett.5b00256

Tatiana, A. M., \& Philomena, M. B. (2021) Appraisal and identification of different sources of smell by primary school children in the air quality test chamber of the SenseLab. Intelligent Buildings International, 13(2), 142-155.

https://doi.org/10.1080/17508975.2019.1682493

Teleszewski, T., \& Gładyszewska-Fiedoruk, K. (2019). The concentration of carbon dioxide in conference rooms: a simplified model and experimental verification. Int. J. Environ. Sci. Technol., 16, 8031-8040. https://doi.org/10.1007/s13762-019-02412-5

Tham, K. (2016). Indoor air quality and its effects on humans-A review of challenges and developments in the last 30 years. Energy and Buildings, 130, 637-650.

https://doi.org/10.1016/j.enbuild.2016.08.071

Tu, Z., Li, Y., Geng, S., Zhou, K., Wang, R., \& Dong, X. (2020). Human responses to high levels of carbon dioxide and air temperature. Indoor Air, 00, 1-15.

USEPA. (2020). Volatile Organic Compounds' Impact on Indoor Air Quality. [Online] 


\section{Macrothink}

Environmental Management and Sustainable Development

ISSN 2164-7682

2022, Vol. 11, No. 1

Available: https://www.epa.gov/indoor-air-quality-iaq/volatile-organic-compounds-impact-in door-air-quality

USEPA. (2020). Carbon Monoxide's Impact on Indoor Air Quality. [Online] Available: https://www.epa.gov/indoorair-quality-iaq/carbon-monoxides-impact-indoor-air-quality

USEPA. (2020). Indoor Particulate Matter. [Online] Available:

https://www.epa.gov/indoor-air-quality-iaq/indoorparticulate-matter

Vehviläinen, T., Lindholm, H., Rintamäki, H., Pääkkönen, R., Hirvonen, A., Niemi, O., \& Vinha, J. (2016). High indoor $\mathrm{CO}_{2}$ concentrations in an office environment increases the transcutaneous $\mathrm{CO}_{2}$ level and sleepiness during cognitive work. J. Occup. Environ. Hyg., 13, 19-29. https://doi.org/10.1080/15459624.2015.1076160

Wang, Z., Bai, Z., Yu, H., Zhang, J., \& Zhu, T. (2004a). Regulatory standards related to building energy conservation and indoor air quality during rapid urbanization in China. Energy Build, 36, 1299-1308. https://doi.org/10.1016/j.enbuild.2003.09.013

Weschler, C. J., \& Nazaro, W. W. (2012). Svoc exposure indoors: Fresh look at dermal pathways. Indoor Air, 22, 356-377. https://doi.org/10.1111/j.1600-0668.2012.00772.x

Weschler, C. J., \& Nazaro, W. W. (2014). Dermal uptake of organic vapors commonly found in indoor air. Environ. Sci. Technol, 48, 1230-1237. https://doi.org/10.1021/es405490a

WHO. (2018). Household air pollution and health. [Online] Available:

https://www.who.int/news-room/fact-sheets/detail/household-air-pollution-and-health

Wilhite, H. (2009). The conditioning of comfort. Build. Res. Inf., 37, 84-88.

https://doi.org/10.1080/09613210802559943

Wolkoff, P. (2013). Indoor air pollutants in office environments: Assessment of comfort, health, and performance. International Journal of Hygiene and Environmental Health, 216, 371-394. https://doi.org/10.1016/j.ijheh.2012.08.001

Wolkoff, P. (2018). Indoor air humidity, air quality, and health - An overview. International Journal of Hygiene and Environmental Health, 221(3), 376-390.

https://doi.org/10.1016/j.ijheh.2018.01.015

Wolkoff, P. (2018). The mystery of dry indoor air - An overview. Environment International, 121(Part 2), 1058-1065. https://doi.org/10.1016/j.envint.2018.10.053

Wolkoff, P., \& Nielsen, G. D. (2017). Effects by inhalation of abundant fragrances in indoor air - An overview. Environment International, 101, 96-107.

https://doi.org/10.1016/j.envint.2017.01.013

Yu, B. F., Hu, Z. B., Liu, M., Yang, H. L., Kong, Q. X., \& Liu, Y. H. (2008). Review of research on air-conditioning systems and indoor air quality control for human health. International journal of refrigeration, 32. 3-20. https://doi.org/10.1016/j.ijrefrig.2008.05.004

Zhang, X., Wargocki, P., \& Lian, Z. (2017). Physiological responses during exposure to 


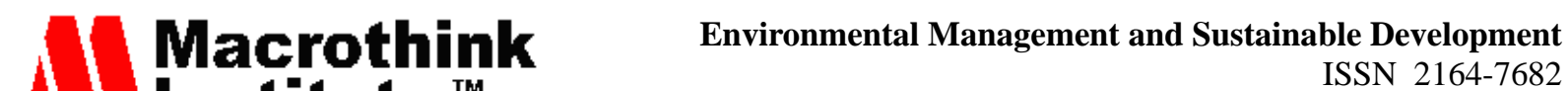 2022, Vol. 11, No. 1}

carbon dioxide and bioeffluents at levels typically occurring indoors. Indoor Air, 27, 65-77. https://doi.org/10.1111/ina.12286

Zhang, X., Wargocki, P., Lian, Z., \& Thyregod, C. (2017). Effects of exposure to carbon dioxide and bioeffluents on perceived air quality, self-assessed acute health symptoms, and cognitive performance. Indoor Air, 27, 47-64. https://doi.org/10.1111/ina.12284

\section{Copyright Disclaimer}

Copyright for this article is retained by the author(s), with first publication rights granted to the journal.

This is an open-access article distributed under the terms and conditions of the Creative Commons Attribution license (http://creativecommons.org/licenses/by/4.0/). 